\title{
Interference Management in Femtocells
}

\author{
Talha Zahir, Kamran Arshad, Atsushi Nakata, and Klaus Moessner
}

\begin{abstract}
Increase in system capacity and data rates can be achieved efficiently in a wireless system by getting the transmitter and receiver closer to each other. Femtocells deployed in the macrocell significantly improve the indoor coverage and provide better user experience. The femtocell base station called as Femtocell Access Point (FAP) is fully user deployed and hence reduces the infrastructure, maintenance and operational cost of the operator while at the same time providing good Quality of Service (QoS) to the end user and high network capacity gains. However, the mass deployment of femtocell faces a number of challenges, among which interference management is of much importance, as the fundamental limits of capacity and achievable data rates mainly depends on the interference faced by the femtocell network. To cope with the technical challenges including interference management faced by the femtocells, researchers have suggested a variety of solutions. These solutions vary depending on the physical layer technology and the specific scenarios considered. Furthermore, the cognitive capabilities, as a functionality of femtocell have also been discussed in this survey.

This article summarises the main concepts of femtocells that are covered in literature and the major challenges faced in its large scale deployment. The main challenge of interference management is discussed in detail with its types in femtocells and the solutions proposed over the years to manage interference have been summarised. In addition an overview of the current femtocell standardisation and the future research direction of femtocells have also been provided.
\end{abstract}

Index Terms-Femtocell, Interference Management.

\section{INTRODUCTION}

$\mathbf{T}$ HE INCREASE in the popularity of wireless networks has lead to the increased capacity demand. More and more users prefer wireless technology as compared to wired services. The wireless access broadly consists of two main technologies, the wireless cellular networks, which mainly provide voice services to users with high mobility and the wireless local area networks (WLANs), which provide higher data rates to users with comparatively restricted mobility [1]. To replace the wired services, wireless networks need to provide high data rate services like the wired networks. Nowadays, the wireless cellular networks have evolved towards providing high data rate services to their users and thus, striving to replace the WLANs as well [2]

With the passage of time, the demand for higher capacity and data rates is increasing. Cisco predicts a 39 fold increase in the data traffic from 2009 to 2014 [3]. A number of technologies and standards have been developed to cope with

Manuscript received 28 July 2010; revised 26 May 2011 and 14 October 2011.

T. Zahir, K. Arshad, and K. Moessner are at Centre for Communication Systems Research, University of Surrey, Guildford, GU2 7XH, United Kingdom (e-mail: T.Zahir@surrey.ac.uk).

A. Nakata is at Mobile Radio Access Network Division, NEC Corporation, 1753, Shimonumabe,Kawasaki, Kanagawa 211-8666, Japan. this increasing demand. The standards like 3GPPs High Speed Packet Access (HSPA), Long Term Evolution (LTE) and LTE advanced, 3GPP2s Evolution-Data Optimised (EVDO) and Ultra Wide Band (UWB) and Worldwide Interoperability for Microwave Access (WiMAX) have been developed to provide high speed communication to end users [4]. To achieve high data rates, signals with high Signal to Interference plus Noise Ratio (SINR) should be received, keeping in mind that transmitter should not cause significant interference to other users by transmitting high power signals. High data rates also require higher order modulation and coding schemes, which are currently used in the above mentioned standards. However, higher order modulation and coding schemes are more susceptible to noise in a given environment. On the other hand, capacity is generally increased by proving larger number of channels per area (cell). This is possible by reducing the area of each cell and thus increasing channel reuse. Classical approaches like Cell Splitting and Cell Sectoring are widely used in current wireless standards to increase system capacity [5], [6]. Efficient interference avoidance and mitigation techniques are used to reduce the overall interference, as the distance to the other cell using the same channels is reduced [7], [8].

Demand for cellular services can originate from indoors as well, that is why it is important for cellular networks to provide good quality coverage to indoor users as well. Study by ABI research shows that in the future, more than $50 \%$ of voice calls and more than $70 \%$ of data traffic is expected to originate from indoor users [9]. Another survey shows that $30 \%$ of business and $45 \%$ of household users experience poor indoor coverage [10]. The new multimedia services and high data rate applications intensifies the need of good quality indoor coverage. Hence, providing good quality indoor voice and data services is of great importance. This would also be beneficial for the cellular operators in the form of increased revenue and reduced churn.

Mobile cellular networks have gained reputation for poor indoor coverage resulting in inferior call quality, QoS issues becomes more predominant as mobile users begin using $3 \mathrm{G}$ services. Due to the penetration losses, the indoor user requires high power from the serving Base Station (BS), which means other users would have less power and as a result the overall system throughput is reduced. It is also very expensive to have a large number of outdoor BSs to meet the needs of a high capacity network. The large number of BSs would pose larger burden on network planning and optimisation as well. The modulation and coding schemes for high data rates used in the standards mentioned above, require good channel conditions, which means that in the case of indoor coverage, QoS cannot be guaranteed due to the variations in channel conditions [11]. 
This emphasises the need of having some indoor coverage solutions, for example picocells, Distributed Antenna Systems (DAS) and relays or repeaters. Picocells are very small cells, providing coverage to a limited indoor area [12]. These are located inside large buildings, which are categorised as hotspots (e.g airports, shopping malls, universities). Picocells work the same way as macrocells and are connected to each other and macrocell BSs through cables. The DAS is another good solution for the indoor coverage problem. This system comprises of a number of distributed Antenna Elements (AEs) and a home Base Station (BS) [13]. The antenna elements are connected to the home Base Station offline through dedicated lines, usually optic fibre cables or dedicated RF links. This can provide good quality communication to areas where outdoor BSs cannot reach. In addition to good quality indoor coverage, DAS can also reduce the transmit power which leads to reduced interference and hence high capacity. It is one of the popular solutions among vendors as it is less expensive as compared to picocells and microcells. The AEs in a DAS are distributed over the area of interest, these AEs comprise of RF transceivers and relays information back to the BS, where all the processing is done [14], [15]. Although picocells and DAS provide good and cost effective alternatives as compared to the outdoor macrocell, these are still too expensive to be deployed for home and small office users. It would be expensive and impractical to install base stations (Picocells and additional antennas) in every residence and small office. Moreover, the overall network processing load would also increase as the number of picocells increase.

Another interesting and hot topic is the relaying in LTE advanced for the indoor environment [16]. As LTE advanced is set to provide high data rates to end users, it would also require an indoor system where it can provide full functionality to the indoor users. In this approach a wireless relay is placed inside a building to compensate the penetration loss caused by the walls of the building. The relaying is mainly performed in two types, Amplify and Forward relaying (AF) and Decode and Forward relaying (DF) [16], [17]. In AF relaying mode, the relay terminal after reception of the signal, amplifies the signal and retransmits it. In this mode, the received signal can be a disrupted one due to noise and fading and can cause the channel capacity to decrease. On the other hand, in DF relaying, the received signal is first decoded and demodulated before retransmission which reduces the overall noise level. It is observed that mostly the DF relaying technique is more advantageous as compared to AF relaying [18].

With the growing demand of innovative $3 \mathrm{G}$ services, most industrial critics see significant potential for the use of technology, so called femtocells [2], [4], [11], [19]-[21]. Femtocells, also known as home base station are small, low power access points and visually look like an ordinary wireless router. These indoor access points are installed by the users, which creates a small wireless coverage area and connect user equipment (UE) to the cellular core network through subscribers broadband internet access [4], [11]. The access point known as Femtocell Access Point (FAP), works as BS, enabling high quality voice, data and multimedia services to be delivered to mobile devices in indoor settings. The FAP can be connected to the operators core network through users DSL, optical fibre or cable broadband connection. Other wireless last mile technologies like Wi-Fi can also be used for the purpose of connecting to the operators core network. In rural areas, where there is no broadband internet connection, a satellite internet connection might also be feasible. However, providing good QoS through a satellite backhaul internet connection might be a big challenge. Compared to the afford-mentioned techniques femtocells provide a better indoor coverage solution but face many challenges. Femtocells would require some portion of spectrum from the operators for its operation. This can be a separate portion of spectrum allocated by the operator or the same portion of spectrum as used by macrocell [19]. In the case of same spectrum being used for femtocells (co channel femtocell deployment), the issue of interference arises. This interference can be between neighbouring femtocells as well as between femtocells and macrocell.

This article provides an overview about femtocells, the advantages that this technology can provide and the key challenges. The main challenge faced by the femtocells is interference management because of their ad hoc deployment. The key techniques that can be used for avoiding and mitigating interference in femtocells are summarised in the remainder of this paper. This document also provides a good overview of the new research challenges in the field of femtocells.

The rest of the article is organised as follows. Section 2 provides a basic introduction to femtocells. Section 3 lists in detail the technical and business aspects of femtocells. Section 4 briefly describes the technical challenges faced by femtocells. The types of interference appearing in femtocells and the main interference mitigation schemes are provided in section 5. Section 6 explains the current standardisation activities with regards to the interference management in femtocells and section 7 gives the future directions and conclusion.

\section{WHAT ARE FEMTOCELLS?}

Femtocells are small low powered base stations, which provide radio coverage to the mobile users in an indoor environment. These are installed in an indoor area by the end user just like a Wi Fi router and provide almost all of the cellular functionalities to the end users [2], [4], [11]. The FAP is then connected to the operators core network through the users broadband internet connection. The connection from an end user to the mobile operators core network is shown in Fig. 1. In Fig. 2, a typical indoor femtocell is shown, where different indoor User Equipments (UEs) can connect to the FAP and use data and voice services. Femtocells use the same physical layer technology as cellular networks and are standardised since $3 \mathrm{GPP}$ release 8 , where it is called as Home Node B (HNB) in WCDMA systems and Home e Node $\mathrm{B}(\mathrm{H}(\mathrm{e}) \mathrm{NB})$ in LTE systems. More detail about the femtocell standardisation is provided in section 6 of this article.

One of the important femtocell functions in 3GPP release 8 is Closed Subscriber Group, called CSG. Each H(e)NB provides an access mode that the limited and registered UEs can only connect to the H(e)NB and any other UEs cannot access it as their connection is rejected. Such $\mathrm{H}(\mathrm{e}) \mathrm{NB}$ is used in home and small office and the owner or the owners family can access to the H(e)NB. This access mode control 


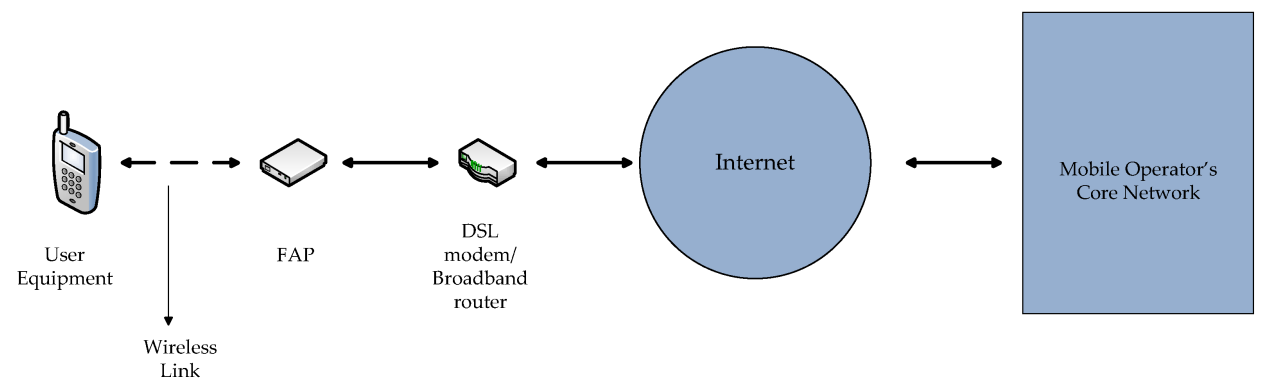

Fig. 1. UE connected to an operator's core network in a femtocell

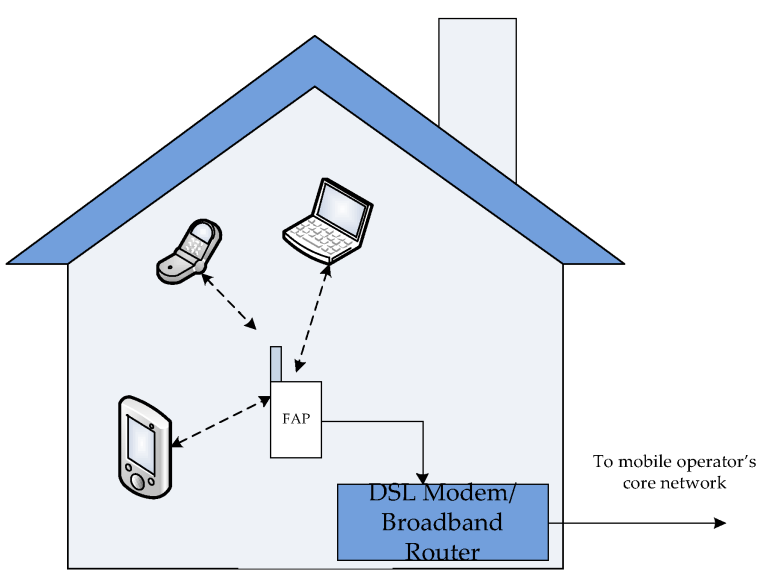

Fig. 2. A typical indoor femtocell

is enhanced in release 9 introducing open access mode and hybrid access mode. The access modes are also described in detail in section 4.

Femtocells are deployed within a macrocell in an ad hoc fashion and any user can deploy femtocells in its home and even can move femtocells from one location to another. Therefore, it is a challenging problem for operators to manage radio resources dynamically [20], [21]. It also requires efficient self organising techniques to make sure it is aware of its surrounding environment and should have distributed optimising techniques to mitigate any interference. Furthermore, in case of dense co channel femtocell deployment where spectrum shortage may occur, it is also desirable for the femtocell to have the functionality of opportunistic spectrum access. This requires that the femtocells should have cognitive functionalities, which makes it more intelligent. The femtocells having cognitive functionalities are called here as Cognitive Femtocells, which due to its extra capabilities can provide efficient solutions to the challenges faced due to dense femtocell deployment in future [22]-[24]. Cognitive femtocells have the capability to sense spectrum in the surrounding environment to locate any vacant spectrum portions (white spaces or spectrum holes). These spectrum holes are then used by the cognitive femtocells to provided connectivity to its users. They can collaborate and cooperate with neighbouring cognitive femtocells for more accurate spectrum sensing. In the case of unavailability of spectrum holes, cognitive femtocells can then use the licensed band for its operation like the normal femtocells [25], [26]. It should be noted here that the term cognitive femtocell is used to show that the femtocell is having extra cognitive capabilities and it can also be just called as femtocells.

The concept of femtocells dates back to the 1999, where Bell Labs first studied a home base station. The Alcatel announced a GSM based home base station to be brought to the market in 2000 [27]. Their demonstration units proved to work through a Plane Old Telephone System (POTS) line, but were unable to make it the market due to the high cost of the equipment. After this, in 2002, Motorola announced its $3 \mathrm{G}$ home base station but the concept was still very new [27]. This concept became more famous in 2005 and the actual term femtocell was coined in 2006. A number of companies started trials and demonstrations.

A not-for-profit membership organisation was formed by different vendors, operators and research organisations in July 2007 named as Femto Forum [28]. Its main aim is to promote the standardisation and wide scale deployment of femtocells all around the world. It has more than 100 operators and telecom vendors in its members list. It provides an excellent linkage between the new technology and industry. The femtocells became main stream technology when the $3 \mathrm{GPP}$ release 8 introduced the Home NodeB (HNB) and Home e Node B $(\mathrm{H}(\mathrm{e}) \mathrm{NB})$ [29]. It is predicted that the future LTE networks would include femtocells for the indoor cellular coverage. Thus it is likely for femtocells to be deployed at a large scale in the near future.

\section{TECHINCAL AND BUISNESS ASPECTS OF FEMTOCELLS}

\section{A. Technical Aspects}

Femtocells can provide a better solution for the indoor coverage problem. Basically due to small cell radius, the distance between transmitter and receiver is reduced, hence transmitted signal is less attenuated and in turn receiver can receive a good Received Signal Strength (RSS). Generally the quality of a signal at the receiver is measured in terms of SINR. The SINR is a function of the transmitted power from the desired BS, transmitted power from interfering transmitters, shadowing, fading and pathlosses [30]. The penetration losses due to walls cause the interfering signals to be weak. This attenuation is more prominent at higher frequencies that are commonly used in 3G technology for their high bit rate operation. These losses act as insulation to the femtocells and thus, femtocells transmit with low power while maintaining good indoor coverage quality. The good channel conditions enables the femtocells to provide high data rate services 
TABLE I

FEMTOCELl AND WI-Fi SPECIFICATIONS

\begin{tabular}{lll}
\hline \hline Specifications & $3 \mathrm{G}$ Femtocell (HSPA) & Wi-Fi \\
\hline Data Rates & $7.2-14.4 \mathrm{Mbps}$ & 11 and 54Mbps \\
Operational & $1.9-2.6 \mathrm{GHz}$ & $2.4-5 \mathrm{GHz}$ \\
Frequency & & \\
Power & $10-100 \mathrm{~mW}$ & $100-200 \mathrm{~mW}$ \\
Range & $10-30 \mathrm{~m}$ & $100-200 \mathrm{~m}$ \\
Services & Primarily Voice and & $\begin{array}{l}\text { Primarily Data and } \\
\text { Data }\end{array}$ \\
& & Voice \\
\hline
\end{tabular}

to users by using higher modulation and coding schemes. Furthermore, a femtocell usually serves a very small number of users (house residents/office employees) as compared to a macrocell (e.g Vodafone femtocells can support maximum of 4 users), due to which, it can devote a large portion of its resources to the available users. This enables femtocells to provide good QoS to its users as compared to a macrocell, which have to serve larger number of users simultaneously in a large area [19].

Femtocells can solve the spectrum underutilisation problem for the regulators. As there are small cells, the channels are re used more often. Two main modes of femtocell deployments are common [31]. The separate channel deployment and the co channel deployment. In a separate channel deployment, a specific channel is allocated for the femtocell network, which is not used by the macrocell. This is done to avoid interference between femtocell and macrocell users. In the co channel deployment, the femtocell uses the same channels as the macrocell [19]. This is much favoured by the operators because dedicating a certain portion of spectrum for femtocells might be expensive, as spectrum is a precious commodity. The co channel deployment also increases the overall system capacity to a large extend. With the co channel deployment, there is a greater risk of femtocell and macrocell users causing interference to each other [19]. Thus efficient and intelligent interference management is required for a successful co channel femtocell deployment. With the benefits of larger capacity, femtocells also provide a viable solution to outdoor coverage problems. The coverage holes in the footprint of a macrocell can be eliminated with femtocells. In this aspect, the femtocell can provide coverage to macrocellular users which are nearby and in the range of the femtocell. This property of femtocells can be of importance at the macrocell edges.

In a femtocell, the FAP working as a BS is of much importance. Both the FAP and Wi-Fi access point have similarities but have difference as well, both uses internet as a backhaul network and thus the QoS mainly depends on the backhaul. However, the FAP implements cellular technology while WiFi are WLANs and mainly used for data services [32]. Table I shows the main difference between femtocells and Wi-Fi. Fig. 3 [33]-[36] shows some common FAPs developed by various manufacturers. The FAPs are developed based on the required technology, for example $2 \mathrm{G}$ and $3 \mathrm{G}$ femtocells have been developed. Femtocells with newer technology like LTE and WiMAX are also developed.

Various air interface technologies co exist nowadays, which lead to the development of different type of femtocells based

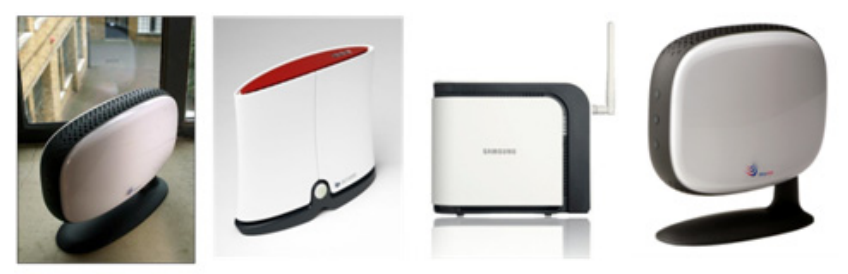

Fig. 3. (left to right) Huawei, Ip.access, Samsung, Ubiquisys

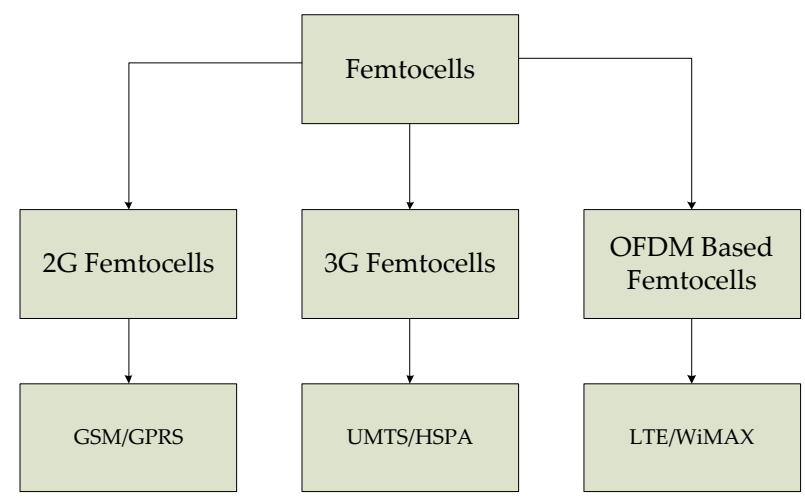

Fig. 4. Types of femtocells based on technology used

on the air interface technology. This shows that the femtocell concept can be applied to wide variety of technologies. Each type of femtocell provides different type of services. The selection of a femtocell based on a particular technology depends on the need of the user. The main types of femtocells are shown in Fig. 4 A brief overview of each type is given.

1) $2 \mathrm{G}$ Femtocells: The $2 \mathrm{G}$ femtocells are based on the Global System for Mobile Communication (GSM) air interfaces. Most of the manufacturers concentrate on the production of $3 \mathrm{G}$ femtocells, as compared to the old GSM, however, GSM holds a huge number of subscribers around the world. Many developing countries like India and Pakistan are still expanding the GSM cellular network, in such a scenario, providing users with 3G and beyond femtocells would be of no use [37]. One of the main reasons of development of $2 \mathrm{G}$ femtocells is its low cost, as compared to the newer versions [38]. One example is the development of GSM femtocells by Ericsson in 2007 [39].

The development of $2 \mathrm{G}$ femtocells was not a great success and many manufacturers avoid manufacturing it because of its drawbacks and economic viability. The main disadvantage is that a GSM femtocell, for data service uses General Packet Radio Service (GPRS), which does not provide high data rates. Hence the use is only limited to good quality voice. It is not likely that a user would purchase a femtocell only for a good quality indoor voice service. Furthermore, the power control in GSM is not flexible enough to cope with the interference issues that would arise due to co channel deployment of femtocells. On the other hand [37] suggests that deployment of $2 \mathrm{G}$ femtocells would be more feasible in the developing countries where the cellular networks are mostly used for voice services only.

2) 3G Femtocells: These femtocells are mainly based on the air interface of Universal Mobile Telecommunication sys- 
tem (UMTS) called UMTS Terrestrial Radio Access (UTRA). These femtocells can provide higher data rates as compared to the $2 \mathrm{G}$ femtocells [40]. The UMTS technology has the capability of connecting through IP based networks, which make it more applicable to femtocells. Unlike the GSM based femtocells, the $3 \mathrm{G}$ femtocells have better power allocation schemes, which can be used to avoid causing interference to the macrocell users. The UMTS femtocells are also standardised by the 3GPP as HNBs [41]. This encourages manufacturers in the development of such femtocells. Femtocells with further enhancements in UMTS are also developed; these are the HSPA femtocells, which provide even better services [11], [42]-[44].

3) OFDM based Femtocells: The WiMAX and LTE femtocells come under this category. As the name suggests, these femtocells use OFDM as their physical layer technology. LTE femtocells are more famous and are considered as the main future indoor technology. These femtocells can provide a variety of high data rate services to the end users [45]. It is also a hot research area nowadays and a lot of research is going on in order to efficiently implement LTE femtocells in the future [46]-[52].

\section{B. Buisness Aspects}

Femtocells can provide an excellent platform for the operators to maximise their revenue, increase network capacity without any further investment in macro cellular network upgrades. Savings also incur as there would be no need to lease land for new sites and electricity cost is also not a burden on the operators anymore. These savings reduce the overall network cost. With the penetration of mobile broadband, offloading the macro network is an extremely hot topic for mobile operators due to the extensive use of smart phones (e.g. iPhone) connected through the mobile broadband network. After the wide scale deployment of femtocells, the burden on the macrocell would be relieved and thus, more resources can be directed towards macrocell users. This can result in the form of providing good QoS to end users and handling capacity needs in a cost effective way to keep business sustainable [53]. For the users, cognitive femtocell promises better indoor coverage and capacity as well as some specific services e.g. notifications of events.

Keeping the savings and benefits in mind, the manufactures still need to be concerned about the price of FAP and services. The femtocell faces competition from the already existing and mature Wi Fi [32]. The femtocell should provide reasonable prices as well as better and versatile services as compared to $\mathrm{Wi} \mathrm{Fi}$, in order to attract more customers. There is also a risk involved in the business as there are few drawbacks from the users point of view. One of the main drawback is that a user must have a broadband internet connection in order to use femtocells. Also the QoS depends on the backhaul connection. Failures in the broadband connection of a customer would result in failure of femtocell. This aspect of broadband internet connection as backhaul can also be of benefit to the operators and they can offer two services (broadband internet connection and femtocell) to a user and thus increase the overall revenue. There is also a problem of operator, as all home residence or guests might not be using services from the same operator but again, this aspect might attract users in one home to use one operator.

Femtocells having cognitive capabilities, mainly opportunistic spectrum access, on the other hand can provide more benefits as a business aspect. The opportunistic spectrum access property of cognitive femtocells enables efficient use of the spectrum. The spectrum is thus efficiently utilised to avoid spectrum underutilisation. These femtocells basically carry most of the cognitive radio advantages combined with femtocell advantages from a business point of view.

Keeping all this in mind, femtocells provide a viable business opportunity. Many manufacturers have started manufacturing their FAPs and operators have started providing them to the users. One example is Vodafone in UK [54]. Vodafone started their trials of 3G femtocells in early 2008 with Alcatel Lucent and Huawei. Recently Vodafone launched its femtocell by the name of sure signal box. It is basically a FAP and costs same as a Wi-Fi access point. The Sure Box provides coverage in a 50 yards radius. The price has been appreciated by many users. In US, Motorola have launched their femtocell named as KeepMeConnected [55]. The FAP is actually a touch screen digital picture, which can be placed anywhere inside a home or office. It allows users to have a single land line connection (VoIP) for both landline and mobile phone. Node-H, a small company providing software stack for manufacturers have recently developed its new software that has cognitive radio capability [56]. This would enable a FAP to perform spectrum sensing in the surrounding radio environment and then configure its self optimally.

\section{TECHNICAL CHALLENGES IN FEMTOCELLS}

Although the manufacturing of femtocells has started, it still faces a number of challenges. These challenges will be of more importance when the deployments of femtocells become denser in urban environment. The main focus of this article is interference management, but other challenges faced by femtocells are also discussed briefly. These are defined in order to give an overall view of a two tier network.

\section{A. Access Modes}

Femtocells can support a limited number of users and therefore, it should be clear as to which user can access a specific femtocell. Currently three access modes have been defined for a femtocell [57], [58].

- Open Access mode: Every user can access the femtocell in this mode and benefit from its services.

- Closed Access mode: in this mode, only specific users can access a femtocell, e.g home residents in a femtocell deployed at a house. The owner can decide as to which user can access the femtocell; it is referred to as CSG by the 3 GPP.

- Hybrid Access mode: this access mode only allows particular outside users to access a femtocell. The conditions of access to a femtocell by an outside user can be defined by each operator separately and entry to any guest or new user can be requested by the owner. 
The open access mode is unlikely to be used by home users as the owner who purchased the FAP and pays for the backhaul and electricity, would not want its femtocell resources to be shared with others. However, this mode can be used in public areas like airports, shopping malls and universities to provide good coverage to the users in that area [59]. Home users generally prefer closed access mode, but in this mode, any outside users near the femtocell experiencing high signal levels from the femtocell would not be able to access the femtocell, if they are not subscribed, thus causing interference. Access modes have a direct impact on the interference in the system and therefore, it should be carefully selected after much analysis. One solution is the hybrid access, which provides a more viable solution by allowing certain outside users to access the resources of a nearby femtocell. Increasing the number of outside users to access a femtocell have a negative impact on the performance of authorised femtocell users, therefore, the number of outside users to be allowed should be carefully selected. The FAP should have the capability to select this number carefully by keeping in view the performance of users authorised to use that particular femtocell [60], [61]. Detailed explanation of the access modes and its impacts are given in [44], [62].

\section{B. Mobility Management \& Handovers}

Femtocells are intended for indoor users and apparently no specific mobility management is necessary. However, with dense femtocell deployment there would be a need for mobility management and handover procedures [45]. This is a key challenge, as in case of dense deployment, it would not be possible for a femtocell to keep track of its neighbours for handover. A femtocell can have a large number of neighbours and these neighbours are created on an ad hoc basis, making it difficult to constantly keep track of neighbouring femtocells. The communication with large number of neighbouring femtocells for handover would also be difficult in limited radio resources. A mobility management scheme is proposed in [45], where an intermediate node is introduced which control the mobility.

Handover in femtocells highly depends upon the access mode being used. The number of handover is very large in the case of open access, while are reduced in closed and hybrid access modes [61]. The handover procedure is also different for femtocells and a number of procedures have been suggested. In [63] a handover mechanism between macrocell and femtocell for LTE based networks is proposed. This handover mechanism basically takes into account the QoS and speed of the UE for handover. Another handover algorithm [64] takes into account the RSS and velocity of UE for handover by using the mathematical concept of sets. Handover procedures for UMTS based networks are also proposed [65], [66] which reduces signalling overhead and number of handovers in femtocells. In [67] different traditional handover schemes are compared and the Mobile Station Controlled handover is suggested on the basis of its performance.

\section{Self Organisation}

Femtocells are deployed by end users and can be turned on and off at any time, hence the deployment is completely random. The number and locations of femtocells can continuously vary within a macrocell. This makes the classic network planning and design tools to configure and optimise a femtocell network unusable. The femtocells need to be intelligent enough to autonomously integrate in a radio access network [68]. They need to be able to self configure and optimise without causing any impact on the existing cellular system. Such functionality of a femtocell would enhance its performance in the form of increased capacity, better QoS and reduced interference to the macro network. The introduction of self organisation in wireless networks was to achieve reductions in the operational expenditure (OPEX) by removing any human involvement in operational tasks of the network, optimise network capacity and enhance QoS. The self organisation mainly comprises of self configuration, self optimisation and self healing [69]-[71].

- Self Configuration: Normally the self configuration phase in wireless networks occur due to any event like addition of new cell sites and addition or removal of network features. In case of femtocells, in addition to the above, the femtocell needs to configure itself whenever it is moved to a new location or rebooted. Prior to operation and optimisation the femtocell needs to sense the environment and configure many parameters like pilot power and neighbour list.

- Self Optimisation: In this phase, intelligent techniques are applied to obtain updated and acceptable network parameters. In femtocells, the optimisation phase needs to make sure all the network parameters (transmit power, physical resources, access modes, admission control, handover control etc) are tuned to an acceptable level. This is a continuous phase which keeps on updating the parameters for an optimised performance of the femtocell.

- Self Healing: In the case of any incidents, the self healing phase tries to resolve the problem occurred to any possible extent. When the problem causing failure is resolved, it should get back to its normal settings.

In order to operate successfully in a dense deployment, the femtocells need to have efficient self organising capabilities. Research to obtain such capabilities is underway and many efficient techniques have been proposed. In [68] a self initialising technique and preamble design for femtocells based on IEEE 802.16e is proposed. The proposed scheme uses the self organised power control method presented in [19]. Macrocell users in the proposed scheme are able to detect a macrocell BS, even if they are located near to a femtocell. The results also show improvement in the throughput of femtocell and macrocell inside the coverage area of a femtocell. Another scheme for femtocells based on IEEE 802.16e named network assisted femtocell BS management scheme is introduced in [72], which reduces the problem of large number of scanning due to large number of neighbours. The serving BS broadcasts information to the femtocell about neighbouring femtocells which helps avoid wasting any air resources and improve the overall performance of a femtocell. An efficient self optimised coverage coordination scheme is presented in [73] where a femtocell adjusts its transmit power based on interference power received at femtocell downlink. 
Initially the femtocell measures the average received pilot power from neighbouring femtocells and macrocells and selects the strongest signal. It then adjusts its own power in such a way that the received power at the femtocell edge is identical to the strongest pilot power received at that location. The algorithm is able to self optimise and perform optimistically.

Currently, many cognitive radio capabilities are under research for femtocells, in [74] a flexible femtocell management scheme is presented. A network decision entity called Dynamic Self Organising Network Planning and Management (DSNPM) is used for reconfiguration. DSNPM includes optimisation procedures and cognitive capabilities that enable it to adapt to environment changes in a timely manner. Two approaches in [52] propose cognitive capabilities for an OFDMA based femtocell. The femtocells first dynamically senses the air interface and then tunes the sub channel allocation according to the sensing results in such a way that the overall inter cell interference is kept minimum and capacity kept at maximum. As the number of femtocells increase in an area, the problem of self organisation would become more challenging and hence there is a need of more research in this area.

\section{Security}

Providing efficient security to femtocell networks is one of the key challenges. In the case of open access mode, security is of much importance as the users private information needs to be protected. The femtocell network is prone to many security risks. For example, the private information of subscriber travels over the backhaul internet connection. This data can be hacked, which would breach privacy and confidentiality [37].

The femtocells are also prone to Denial of Service (DoS) attacks. A hacker can overload the link between a FAP and mobile core network. This would prohibit a subscriber to connect to the core network and the femtocell service would not be available. Security is also required to prevent unwanted users to access a femtocell network and use the resources. This is mainly for the close access mode, where only specific users can access a femtocell [75].

Due to these threats, operators and manufacturers provide some level of security. Mainly the Internet Protocol Security (IPSec) is used to provide security to the link between FAP and operators core network. There is a security gateway in the operators core network and when the FAP wants to connect to the core network, a secure tunnel is established between the FAP and the security gateway. All the data to and from the femtocell travels through the secure tunnel, hence making the data more secure [76]. In [75] a number of security threats like eavesdropping, man-in-the-middle attack and compromising subscriber access list have been pointed out. These threats have not been addressed sufficiently till date and thus the author proposes improved authentication and key agreement mechanism for H(e)NBs. With the increasing number of femtocell deployments the security issue would become more and more serious. Therefore, there is a need of extensive research in this area.

\section{E. Timing \& Synchronisation}

In a wireless system, the timing and synchronisation is of great importance. A crystal oscillator is used for the internal clock. The internal clock helps accurately align packets between transmitter and receiver. It also helps to maintain specific frequency alignment. The error in synchronisation and timing can cause Inter Symbol Interference (ISI) in OFDM systems [49]. The crystal oscillator is the main portion of the FAP that count towards its cost. Good quality oscillators are expensive, which will increase the overall femtocell cost.

Synchronisation for the femtocells can also be achieved through the backhaul Asymmetric Digital Subscriber Line (ADSL). The FAPs use the ADSL to connect to the clock of the operators core network and use that clock to synchornise itself. However, there can be unpredictable delays on the internet connection due to varying traffic and thus errors in the synchronisation. The IEEE 1588 [77] specify the Precision Time Protocol (PTP) for synchronising independent clocks with different precision. However, the IEEE 1588 still make synchronisation errors between the master clock and the slave clock [78]. An enhanced synchronisation algorithm based on IEEE 1588 is proposed in [79] where the asymmetry is taken into account and any offsets in timing are removed.

Another approach to solve the problem of synchronisation is to use GPS receiver within the femtocell. The GPS services would be used to provide timing and synchronisation to the femtocell which is a cost effective solution. The GPS can also be used for the localisation purpose, which can be used to provide the subscriber with local news and information. In case of emergencies, the location of femtocell will be known which can be much helpful. The information can also be helpful in interference management in case of networked femtocells. However the disadvantage in using GPS for indoors is that the GPS signal suffers significant amount of attenuation and may not be able to provide accurate synchronisation. Most of the areas nowadays receive a good quality television transmission and this can be used to provide synchronisation to femtocells. Femtocells can have an advanced TV receiver built in, which can provide accurate timing and synchronisation [80].

A femtocell can also take help from its neighbouring femtocells in order to be synchronised with the rest of the network. A frame synchronisation method for femtocell BS in TDD systems is proposed in [81], this scheme uses transmissions from any adjacent BSs to establish synchronisation. Another similar approach is introduced in [82], where the neighbouring femtocells preamble signal is used to align the femtocell frames. Timing and synchronisation is a key challenge for femtocells, and intelligent algorithms need to be developed to overcome this challenge.

\section{F. Interference Management}

This is one of the most important challenges for dense deployment of femtocells. As described before, the operators prefer co channel deployment of femtocells to sufficiently increase the overall capacity, but this causes the problem of interference [11]. As many femtocells and the macrocell are using the same portion of spectrum, these can cause interruptions to each other. 
Interference management in femtocells and the different techniques used to mitigate interference are explained in detail in the next section.

\section{INTERFERENCE MANAGEMENT IN FEMTOCELLS}

Due to the deployment of small indoor base stations, the cellular architecture changes and now consists of two tiers or layers [12], [19], [50], [82], [83]. The first tier or layer is the conventional macrocellular network while the second tier or layer is the femtocell network. The new architecture is thus called two-tier or two-layer network architecture. The new layer, called the femtocell layer is an unplanned and random distribution of femtocells. This has a number of advantages in the form of capacity, coverage and quality [21], However, the new architecture also brings forth new problems and design challenges. Among these challenges the interference management is of importance. The femtocell is preferred to be deployed in co channel fashion, which is using the same frequency bands as the macrocell, to achieve higher capacity. This in return, gives rise to severe interference management challenges [84].

This section explains the main types of interference faced in the two-tier network architecture. The interference problems faced in both uplink and downlink is explained. The development of femtocells is mainly in the CDMA and OFDMA technologies. Therefore, interference faced by these two technologies is more elaborated in this section. In the end key interference management algorithms researched so far are discussed.

\section{A. Types of Interference in a Two Tier Network}

The two-tier architecture enables us to divide the interference in to two main types. These are elaborated in Fig. 5 and explained below.

1) Co-tier Interference: This type of interference refers to the interference caused by network elements that belong to the same tier or layer of network [11]. In the case of femtocells, it is the interference caused to a femtocell by another femtocell as shown in Fig. 6. Usually the femtocells causing interference to each other are immediate neighbouring femtocells, as they are close to each other. The deployment of femtocell is random and they can be deployed very close to each other in apartments, where the wall separation might not be enough to avoid causing interference to each other. In the case of dense deployment, where there might be a number of neighbouring interferers, the overall interference observed at a femtocell can be higher than any of the individual interfering femtocells. To establish a communication link, the SINR value should be above a certain threshold. If the SINR at a certain femtocell location is lower then a defined threshold due to co-tier interference, it would be impossible to create a communication link and thus a dead zone would be created. The SINR threshold level is usually defined by the air interface technology in use and can be different for different requirements of QoS [49].

The access methods used in femtocells have a huge impact on the overall interference. The co-tier interference is more severe in closed access as compared to the open access [44]

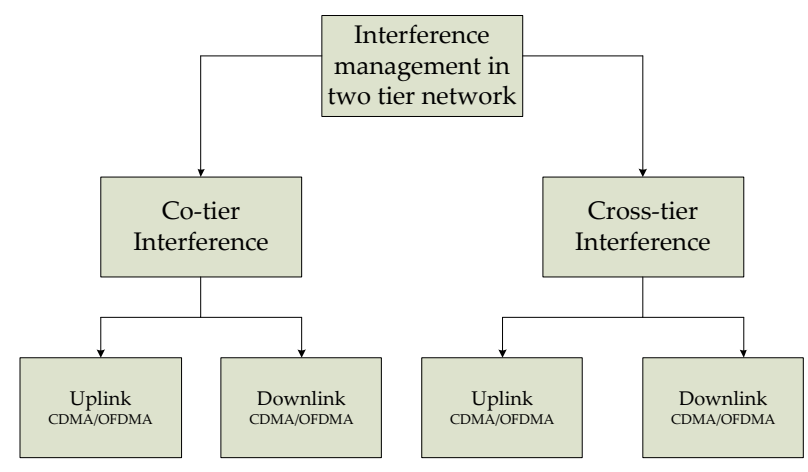

Fig. 5. Types of interference in two tier femtocell network

Due to this, the dead zones in closed access are larger as compared to open access. The dead zones also depend on the QoS requirement of each service. If a service requires higher SINR, it might not be possible to provide the service near the windows or edges of a femtocell. So the dead zone for such services would be larger as compared to other services that do not require comparatively high SINR.

The uplink co-tier interference is caused by the femtocell user equipment (UE). The femtocell UE acts as a source of interference to the neighbouring FAPs. For example, in a CDMA system, the immediate neighbouring femtocell UEs are the main source of uplink interference [49]. If a UE in the neighbouring femtocell transmits at a high power, it will affect the victim femtocell and the performance will be degraded. In this case, an FAP should impose power limits on its UEs in order to control the noise level at neighbouring FAPs. The 3G system like UMTS and High Speed Uplink Packet Access (HSUPA) applies intelligent power control techniques to limit the uplink interference. In these systems, the FAP is able to sense the surrounding radio environment and gather information about any near by femtocell UEs. It then sets the transmit powers of its UEs based on the gathered information.

In the case of OFDMA femtocells, the FAP should sense the surrounding radio environment for certain sub channels. A UE would require certain number of sub channels depending on the QoS, the FAP should then allocate sub channels that are subject to lower level of interference. As compared to the CDMA, the OFDMA system provides better chances of avoiding interference due to the division of spectrum into small sub channels [49]. Different strategies are described later in this section.

The downlink co tier interference is caused by an FAP, where the FAP is the source of interference as it causes interference to the neighbouring femtocell UEs [11]. Due to the close deployment of femtocells, there is a high chance of power leaks through windows, doors and balconies. These power leaks cause interference to the neighbouring UEs. In a CDMA system, this would add up to the noise level and create dead zones around the femtocell [11]. To avoid such interference the $3 \mathrm{GPP}$ recommends using adaptive power control techniques at FAPs. This power control becomes more important in the case of closed access femtocells because a UE in this scheme is not served by the strongest FAP but by 


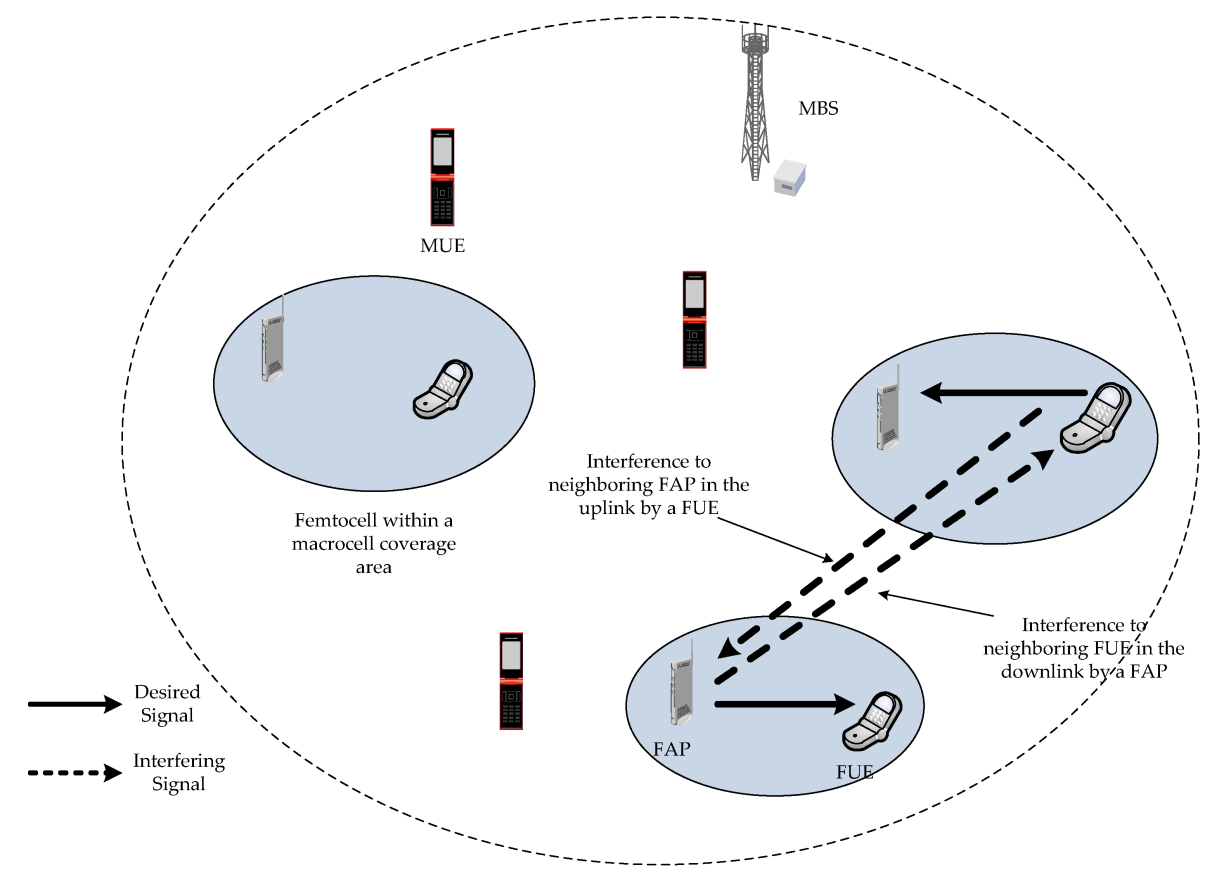

Fig. 6. A scenario showing co-tier interference between neighbouring femtocells

the one to which it is subscribed. Similar to the uplink case, the FAP in the downlink should be able to sense the radio environment and adjust its power accordingly. In the case of OFDMA femtocells, it again depends on the allocation of sub channels. If different sub channels are used by the source of interference and the victim, interference would be avoided.

2) Cross-tier Interference: This type of interference is caused by network elements that belong to different tier or layer of the network. For example, an FAP can cause interference to the downlink of a macrocell UE nearby as shown in Fig. 7. Also a macrocell UE can cause interference at the uplink of a nearby FAP. Femtocells would cause large amount of interference to neighbours that are using macrocell services for indoor purpose. This problem becomes more severe in the case of closed access mode [44]. The macro UEs would receive strong signals from the close by neighbour, to which access is denied and there would be huge dead zones around the femtocell. To cope with the cross-tier interference, spectrum splitting is also proposed. However, this is a less efficient technique, as spectrum is costly and scarce as well. In the case of having separate spectrum portion for the femtocell tier, there would be no cross-tier interference. However, if the bands are adjacent to each other in the frequency domain, there can be adjacent channel interference. Hence, effort is required to mitigate the adjacent channel interference as well.

The cross-tier uplink interference can take place when a femtocell UE acts as a source of interference to the macrocell BS [49]. In the case of a CDMA system, power control is used in order to prevent femtocell UE from causing interference to the macrocell BS. The FAP should sense the environment and not ask for higher powers from its UEs. The femtocell UEs are normally close to the FAP and do not transmit at enough high powers to cause interference to macrocell BS. In the case of open access mode, the users are allowed to connect to any layer, depending on the quality of the received signal at the time. This enables the use of minimum power by both femtocell and macrocell and hence the interference can be reduced.

Another case of cross-tier uplink interference is when a macrocell UE transmits at high power near a femtocell [49]. This will cause interference at the FAP. The femtocells are normally isolated, due to the wall penetration, but still in some cases the macrocell UE can cause sufficient interference to the femtocell.

In the case of OFDMA, the same two types of uplink crosstier interference can occur. The first type of interference as defined above for CDMA can also occur in OFDMA systems if the femtocell is located near the macrocell BS. If a femtocell UE is transmitting with high power on certain sub channels near a macrocell BS, these sub channels become unusable for the macrocell BS and hence the overall efficiency is reduced [12]. In this case, the power of the femtocell UE should be restricted and there should be bound on the upper limit of transmit power of a femtocell UE. In the second case of interference, where a macrocell UE is transmitting with high power because of being away from the macrocell base station, the femtocell should allocate different sub channels in order to avoid interference.

The downlink cross-tier interference can be caused by an FAP to a close by macrocell UE [11]. In the case of closed access mode, the area around the femtocell becomes dead zones for macrocell UE. There can be power leakage through windows and doors from an indoor located FAP to a nearby macrocell UE. In the case of CDMA co channel deployment; there is a need for adaptive power control, because of the changing circumstances. The adaptive power control can 


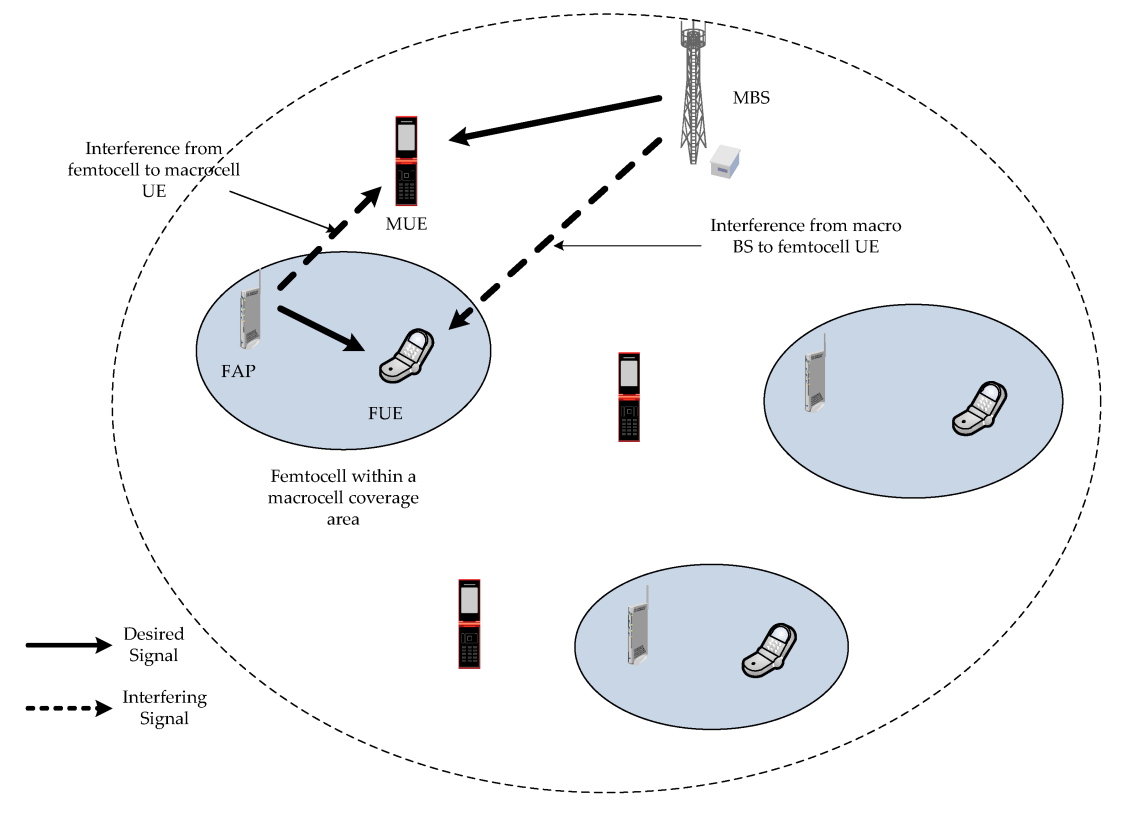

Fig. 7. A scneario showing cross-tier interference between femtocell and macrocell

provide FAPs with a variety of options and hence mitigate interference. If the femtocell is located near to the macrocell BS, the femtocell size would shrink because of the interference from the macrocell BS. In this situation, the femtocell UEs can have coverage only when they are located very near to the FAP. In a scenario, where a femtocell UE is near the window of a house having FAP, it is more likely that the UE near the window will connect to the macrocell BS instead of the indoor FAP. The Femto forum investigated such a scenario and deduced that a throughput of $14.4 \mathrm{Mbps}$ can be achieved using HSDPA femtocells, when the femtocell UE is located 250 meters from a microcell and 1000 meters from a macrocell.

In the case of OFDMA femtocells, the downlink interference management is mostly dependent on the allocation of sub channels. The FAP would not cause any interference to a macrocell UE, if the macrocell UE uses a different set of sub channels.

\section{B. Interference Management Techniques}

The various types of interference introduced in the network due to the addition of a new femtocell layer have been explained in section 5.1. The types of interference are perceived differently in different air interface technologies. In the two tier network architecture, the interference perceived from the point of view of CDMA and OFDMA was described. Each of these technologies uses different techniques to manage the co-tier and cross-tier interference. The research is still going on in this area and many schemes have been proposed. Some main schemes would be summarised in this portion. The main emphasis is on interference avoidance, for reasons explained later, but other interference management techniques are also briefly described. Fig. 8 shows the block diagram of all the techniques explained.
1) Interference Cancellation in Femtocells: These are the class of schemes that reduces interference at the receiver end, which means interference is cancelled after the signal is received. The interference cancellation is defined by Andrews [85] as the class of techniques that demodulate/decode desired information, and then use this information along with channel estimates to cancel received interference from the received signal.

Two classical ways of interference cancellation used extensively in wireless networks are Successive interference cancellation (SIC) and parallel interference cancellation (PIC) [85][90]. PIC detects all users simultaneously. This initial estimate can be used to cancel interference in near future and parallel detection is repeated and this process is repeated over several stages. The PIC is also known as multistage interference cancellation [91]. On the other hand, SIC detects one user per stage. The strongest received signal is detected first, then the next strongest, and so on [92]. PIC has decreased latency but higher overall complexity because $\mathrm{N}$ number of users must be detected in parallel and there are $\mathrm{P}$ cancellation stages. Latency is proportional to $\mathrm{P}$, which is much smaller than $\mathrm{N}$ for cellular systems, but complexity is proportional to PN. SIC have complexity and latency proportional to N, and this latency may be unaffordable if there are many users with real time data [85]. To have a better scheme, we have Multistage SIC, which is smoother trade off between the two techniques [93]. A group of users are detected in parallel, and then has their aggregate interference subtracted from the composite received signal, and then another group is detected in parallel.

Majority of the interference cancellation techniques require knowledge of the characteristics of the interfering signal. It also requires antenna arrays at the receiver system to cancel any interference. These make these techniques less suitable 


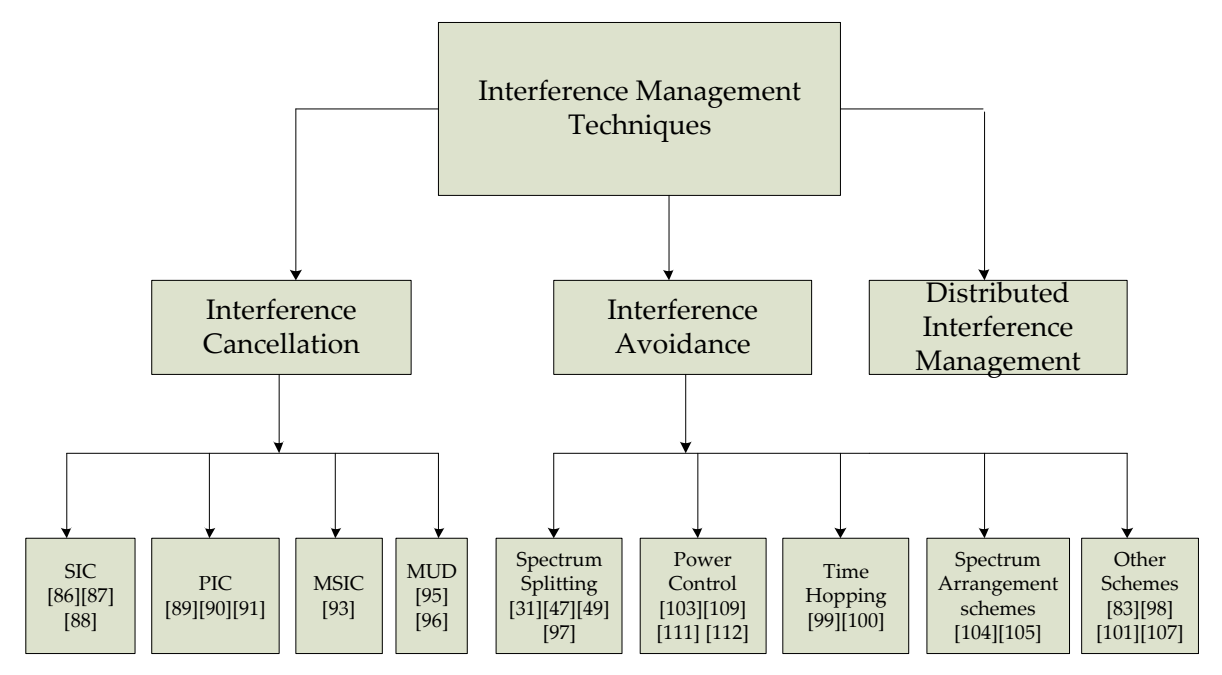

Fig. 8. Different interference management techniques in femtocells

for UEs and are mostly suitable for implementing in base stations (macrocell BS, FAP) and hence mostly used for the uplink interference management [94].

Multiuser detection (MUD) works on the same principle and identifies the signature of each user. It selects the most probable signal out of $\mathrm{K}$ number of users, depending on its observations and channel state information. It is well suited for the CDMA systems, where each user has its own spreading code and hence having a unique waveform and the near far effect needs to be eliminated. MUD in this case helps to detect the different CDMA users and all the users can benefit from joint detection [95]. The common detectors used to counter the multiuser interference in CDMA channels are the decorrelating detector and linear minimum mean square error (MMSE) detectors [96]. These detectors require prior knowledge about the system like signature waveform and received amplitudes or some training data should be provided. These algorithms can be complex and difficult to implement and are frequently used for uplink with more optimal variants [85].

2) Interference Avoidance in Femtocells: Due to the ad hoc nature of the femtocell deployment it is difficult to manage femtocells from a centralised controller as the cell planning in this case cannot be done. It is therefore preferred to induce intelligence into the FAP, to enable it to self organise and cope with interference without any centralised controller. Different femtocells depending on their location and environment would face different interference challenges without any knowledge of the global network and therefore, it is important to have distributed self organisation and optimisation schemes. The FAP should be able to cope with most of the situations and make sure the user enjoys good quality service of femtocells. Intelligent interference avoidance technique is thus of great importance and more research needs to be done in this area. In this section the interference avoidance schemes proposed in the recent research are summarised. First the general interference avoidance techniques are summarised and then techniques used for specific physical layer technologies (CDMA and OFDMA) are discussed in the following sub sections. In the end, distributed optimisation schemes for femtocells are also described.

The main interference challenges faced are the co-tier and cross-tier interference as described in section 5.1. To cope with the cross-tier interference, initially spectrum splitting was suggested [97]. It was recommended that a spectrum band should be divided into two portions. One portion should be allocated for use of macrocell users and the other portion would be used for femtocell operations. This would only leave the co-tier interference to cope with. However, due to the high cost and scarcity of spectrum, this technique would lead to reduced efficiency. In some cases, where there is very dense deployment of femtocells, and the cross-tier interference is hard to manage, it is suggested that separate portion of spectrum should be used for the femtocell operations [31]. In the case of OFDMA system, separate sub channels are allocated to the femtocells to mitigate the cross-tier interference. Another approached proposed in [31] is to have a limit on the maximum number of femtocell users in a macrocell. Given the properties of femtocells as plug and play device, there can be any number of femtocells in a macrocell. It is also hard to know the exact number of femtocells at a given time, thus, this approach seems impractical.

Power control is a key technique in the interference avoidance, especially in dense femtocell deployment. If the transmit power of a femtocell is controlled and optimised, the outdoor macrocell UE can be protected sufficiently. One such technique is proposed in [98], where femtocell network optimisation is performed with constraints on the indoor coverage and the interference caused by femtocell BS to the macrocell UEs outside. The optimisation problem is formulated as a mixed integer problem and as a result, the maximum transmit power and operational frequency of femtocell is obtained. This leads to a scenario where the femtocell BS does not cause sufficient interference to the macrocell UE and at the same time the femtocell having enough indoor coverage area. The drawback of this technique is that it is complex and time consuming and would not be feasible for implementation in a FAP. A 
simple technique in [99] provides power control to femtocells to avoid causing interference to nearby macrocell users. It is based on the assumption that the femtocell takes information about macrocell users from the macrocell base station. Once the macrocell user in under interference, the nearby femtocell reduces its transmit power.

a) CDMA: Various interference avoidance techniques are proposed for CDMA based wireless systems. One major scheme proposed is the time hopping to reduce the cross-tier uplink interference. In the $3 \mathrm{G}$ system, this is done using Time Hopped CDMA (TH-CDMA). In this scheme, the transmission period is subdivided into small portions during which a user transmits and remains silent for the other portions [100]. If there is no synchronisation between the two network tiers, then each network tier independently chooses its periods. For example, a CDMA transmission period $P$ can be sub divided into $N$ portions or hops. Each user then selects one of the hops (having length $P / N$ ) for transmission. It is observed that this scheme reduces the co-tier and cross-tier interference by a factor of $N$ [101].

A joint hopping scheme can also be implemented by having all the users of one femtocell to transmit in the same time slot. Due to the averaging of aggregate interference in a CDMA based system, the femtocell users would not cause interference to each other. The neighbouring femtocells independently select time slots which reduces the co-tier interference by a factor of $\mathrm{N}$ as well. The cross-tier uplink interference at the FAP is reduced due to the same reason of independently selecting time slots [101].

As described in section 5.1, femtocells at the edge of a macrocell can receive uplink interference due to nearby macrocell UEs transmitting at high power. Similarly the femtocell operating in closed access mode can cause severe interference to the macrocell UE nearby. A study in [102] shows that with constant transmission power a FAP can cause large amount of interference to the macrocell UE. A cell edge scenario in an FDD WCDMA based system has been analysed. The results showed dead zones having size of radius 30 meters in the co channel deployment. The size of these dead zones was reduced to 5 meters when the carriers were separated by $5 \mathrm{MHz}$. It shows that if the carrier separation is less, the interference increases and the size of dead zones also increase. A power adjustment scheme is also proposed in this scenario, where the FAP adjusts its power by observing the macro Received Signal Code Power (RSCP) in the adjacent channel. The use of power adjustment schemes reduces the cross tier interference.

In the case of macrocell UE causing interference to the FAP at the macrocell edge, one solution can be the use of multi sector antennas for FAP. This technique has been suggested in [101] to reduce the cross-tier interference. If an antenna having $\mathrm{S}$ number of sectors is used, the cross-tier interference is reduced by a factor of $\mathrm{S}$. The use of more than one radiating elements have also been proposed in [103], where several antenna elements are used to perform beamforming. It also helps in adopting the coverage area of the femtocell in a way similar to the shape of the indoor area (house or office). Having sectorial antennas would however increase the overall cost and complexity of the FAP and make it less feasible for wide scale deployment.
Power control plays a vital role in the interference avoidance in CDMA systems. The two main and common power control schemes, open loop power control and closed loop power control have also been suggested for femtocells [84]. In the open loop power control, a femtocell UE estimates the maximum allowable transmit power by estimating its cross-tier interference to the macrocell BS. The femtocell UE finds out the cross-tier interference that it will cause to the macrocell $\mathrm{BS}$, and adjusts it power in such a way that the cross-tier interference it is causing to the macrocell BS, should be less than a pre defined threshold. In the closed loop power control femtocell UEs adjust their maximum transmit power based on two things. First is the estimate of additional cross-tier interference at the macrocell BS due to the femtocell UE, which is similar to the open loop technique and second, it also takes into account the Noise and Interference (NI) level at the macrocell BS. The NI level is broadcast to a femtocell UE by the FAP. This NI level is calculated by macrocell BS, which informs the FAP about this through the backhaul network. It is also shown that the closed loop power control technique performs better than the open loop technique. The closed loop power control performs better at the low expense of macrocell throughput. Another solution is provided in [104], where a joint power control, channel management and admission control algorithm is proposed to cope with the co channel interference in the downlink. This algorithm gives higher priority to the macro UEs and provides power control solutions in both distributed and centralized manner.

b) OFDMA: As compared to the CDMA system, the OFDMA system provides much flexibility in the designing of interference avoidance schemes [48]. The OFDMA femtocell needs to know about its surrounding environment which enables the FAP to have more detailed measurement reports from the users and hence allocate sub channels more intelligently. To cope with the cross tier interference, a dedicated spectrum approach can be used [47], [49]. The spectrum would be divided in to two main portions. One portion would be dedicated to macrocell operations, while the other one for femtocell. However, there still can be Inter Carrier Interference (ICI) and Multiple Access Interference (MAI) due to lack of synchronisation, leading to lack of orthogonality. This problem would get even more severe in dense femtocell deployment. In order to have accurate clock timing, each femtocell BS or FAP first calculates its distance from the macrocell BS. If the macrocell BS is at a distance $S$ from the FAP, the FAP delays its transmission for $S / C$ relative to that of the macrocell BS transmission time, where $C$ is the speed of light. This enables somewhat accurate synchronisation, which leads to avoidance of any ICI or MAI [49]. Normally the operators prefer using same spectrum portion for femtocells as it is a more efficient utilisation of an expensive spectrum.

Depending on the type of deployment (co channel, dedicated channel) there is always a trade off between spectrum utilisation and co channel interference. In order to keep a balance, in LTE systems, the deployment of femtocells also known as $\mathrm{H}(\mathrm{e}) \mathrm{NBs}$ can be set to a partial co channel deployment [105]. In this deployment scheme, some channels are reserved for the usage of macrocell, while other channels 
are shared between macro and femtocells. To avoid cross tier interference in such a case, a spectrum arrangement scheme is proposed in [106]. In this scheme, it is assumed that the macrocell knows the portion of spectrum dedicated for macro usage and the portion shared with femtocells. Having this knowledge, the macrocell then develops a database or interference pool. This pool is populated by macrocell UEs which have a threat of co channel interference from the femtocells. These macrocell UEs are thus assigned spectrum from the portion which is dedicated for macrocell usage. Any other macrocell UEs can be assigned any portion of the spectrum, as they do not pose any danger of co channel interference. Another similar scheme for LTE femtocells is presented based on Fractional Frequency Reuse (FFR) [107], where only the sub channels that are not used in the macrocell sub area are allocated to the femtocell. This scheme thus avoids any cross tier interference that would occur because of any near by macro UEs.

Resource allocation is of much importance in OFDMA systems and various schemes have been proposed, such as the Round Robin (RR) and Proportional Fair (PR) schemes [82]. The RR scheme works like a cyclic scheme, each macrocell UE is allocated same time slot. The users are in a kind of queue and the time slot returns to its starting point after going through the queue of users. In the PR scheme, users are given priority based on their needs. A user with a need of higher data rate would be selected first. Results show that the PR schemes perform better than the RR scheme. On the other hand, for a femtocell it is desired to allocate sub channels that reduce the interference and increase the Area Spectral Efficiency (ASE).

A femtocell having cognitive capabilities can avoid interference by using its spectrum sensing functionality. The femtocell can sense the environment and is able to recognise an interference signature [108]. This interference signature enables a femtocell to select specific channels that are not facing interference from the surrounding environment. The idea here is to re use any available channel that would not cause interference to the macro or nearby femtocells. The amount of channel re use varies in different femtocells, depending on its location and environment. However, this would require the FAP to have the capability of intelligently perceiving the radio environment and recognising the interference signature accurately. A similar interference avoidance scheme based on OFDMA in which the femtocell has cognitive capabilities is presented in [109]. This scheme is based on the closed access mode and avoids the cross tier interference between femtocell and macrocell by implying the femtocell to use resource blocks that are used by macro UEs spatially far away from the femtocell. The avoidance scheme also uses spectrum sensing results and scheduling information obtained from macro BS through the backhaul.

A general scheme for dynamic spectrum access (DSA) and power allocation (PA) is presented in [110]. This scheme considers the femtocells are secondary users as in the case of cognitive femtocells and takes a simplified scenario where there are 3 macrocell users (primary users) occupying the 3 available channels. The femtocells each having one user, are randomly distributed and are large in number. The problem is formulated as an optimisation problem and each femtocell is assigned one of the 3 channels that are also used by the primary users. The DSA scheme optimises the channels in such a way that the femtocell having sufficient spatial separation from the primary user would only reuse the same channel. This way, the scenario is basically divided into three zones, where each zone uses the channel of a primary user, which is at a sufficient distance from the zone [110].. The power allocation is also based on the fact that each femtocell adjusts its power in such a way that the maximum interference caused to the surrounding femtocells should not cross a certain predefined threshold. Inter cell coordination is also used for interference avoidance schemes to avoid inter cell interference at cell edges [111]. The research proposes an interference coordination scheme using the downlink multi cell resource allocation with dynamic inter cell coordination. The scheme achieves better performance without any loss in the sector throughput. The scheme can be implemented in femtocells to avoid any interference from nearby macrocell base stations.

3) Distributed Interference Management Schemes: Femtocells have limited knowledge about the global femtocell network which makes the centralised techniques very difficult to implement. Providing sufficient knowledge to the femtocells is possible through the backhaul network, but this would cause much congestion on the backhaul network. Furthermore, as the number of femtocell can be very large, this makes it impractical for the operator to provide large information to the femtocell through the backhaul. In this case, distributed schemes are of much importance. Researchers have provided a number of distributed schemes for interference avoidance in femtocells, some key techniques are discussed.

A distributed power control algorithm is proposed in [112]. for the closed access mode. The paper derives a relation which provides the largest feasible cellular SINR values if a set of feasible SINR values for femtocells are given. In order to reduce the cross tier interference, a distributed utility based SINR approach at the femtocell BS is also proposed, where the power of femtocells causing strong interference is gradually reduced [113]. A distributed dynamic Inter Cell Interference (ICI) avoidance (DDIA) scheme is proposed in [114]. The algorithm introduces the concept of ICI link and two tier scheduling due to which it is able to harmonise all base stations with users adaptively. An interesting study is done in [115], where femtocells are able to decode the BS control channel and make decisions related to transmission based on the scheduling and resource allocation of the macrocell system. The concept is similar to the Type II relays specified in IEEE 802.16j standard. A number of comparisons are done with certain system assumptions.

The importance of distributed power control schemes for HSDPA femtocells have been described in [116]. Two distributed power control schemes have been proposed, in the geo static scheme the transmit power of a femtocell is controlled on the basis of its location. While in the adaptive power control scheme, a target data rate is computed by the network and the transmit power is adjusted to achieve these data rates locally. Another scheme [117] addresses the problem of power control in decentralised OFDMA based femtocell networks and a distributed power control and scheduling algorithm is proposed. The algorithm is able to exploit multiuser diversity 
while determining power level on each sub channel. In [118] the power control objective is modelled as a utility function which is strictly concave with respect to the transmission power. An algorithm with particle swarm optimisation is then developed to obtain the optimal power settings.

Radio coverage optimisation plays a vital role in improving the overall performance of femtocell networks. Due to the lack of global information and central control in femtocell networks, development of distributed coverage optimisation algorithm can be challenging. One such algorithm for joint femtocell coverage area optimisation is proposed in [119]. The algorithm runs individually on each FAP and strives to achieve user load balancing and minimisation of coverage holes and any overlaps. This scheme adjusts the femtocell pilot transmit power and provides 18\% improvement in supported user traffic as compared to the fixed pilot transmit power schemes. Another pilot power minimisation scheme is presented in [120], where the pilot power management for High Speed Downlink Packet Access (HSDPA) femtocell network is studied. The pilot power for HSDPA femtocell is adjusted subject to the instantaneous coverage requirements. A generalised optimisation problem is formulated and a suboptimal analytic solution is provided for each femtocell. Similarly in [121], coverage adaptation is proposed for femtocells where the information about mobility events of indoor and passing by users is used to optimise the femtocell coverage. This in turn also decreases the core network mobility signalling. In [122] another adaptive pilot power model is introduced for femtocells to adapt the transmission power based on position of the users. The scheme uses information about mobility events of the outdoor users to optimise femtocell coverage, which reduces the transmission power according to the user position. Similar work is done by [123], where the femtocell first obtains information about is surrounding environment and uses this information to carry out self configuration and self optimisation to achieve an optimised coverage and minimum interference in the network. A low cost multi element antenna is used with a series of corresponding algorithms mainly based on low complexity shaped beam forming and power adjustment.

Game theory has been used in network resource allocations and is also used in femtocells for power allocation scheme. One such scheme is proposed in [124], where a decentralised power control algorithm that considers loads of individual femtocell is proposed for closed access femtocell networks. A payoff function is derived using fairness and interference to other femtocells. The algorithm is based on a non cooperative game model and the properties of a supermodular game are used to implement the decentralised power control algorithm. This shows that the power of femtocells with less user load is reduced more as compared to femtocells with comparatively larger number of users. Another similar algorithm using game theory for interference management in OFDM based femtocells have been proposed in [125], where femtocells self organise in order to find the most appropriate access strategy. The FAPs strive to find out an optimal strategy for resource allocation under the constraint of inducing a limited amount of harmful interference to the MUE. Game theory has also been used in [126] for a femtocell based Mobile Virtual Network Operator (MVNO) model and power settings are derived based on Nash Equilibrium. The power settings maintain the required QoS level without causing sufficient interference to the MUE.

The problem of co tier interference is also addressed in a distributed algorithm [127]. Fractional frequency reuse (FFR) is used to adjust the fractional frequency reuse factor according to the environment. This is done with the help of femtocell location and interference information and classifies femtocells into different groups, where sub channels are allocated to avoid interference. Allocation of transmit power takes place after the allocation of sub channels, the power is allocated based on the received signal strength information (RSSI) in a distributed fashion.

Distributed interference management schemes are the key solutions for the interference management challenge in femtocells. These schemes are able to address the problems in a way that is suitable for femtocells and hence further research is required in this area.

\section{Open Challenges in Interference Management}

The efficiency of an interference management scheme depends on the specific femtocell scenario. In case of less dense deployment, simple schemes can be helpful and provide sufficient interference management for both the macrocell and femtocell network layers. The main aim is to enable femtocell to be deployed densely and hence, efficient interference management schemes that can cope with the ad hoc nature of femtocells and provide QoS to both macrocell and femtocell users should be developed. It should also be kept in mind that the FAP is a small low powered device and it should be able to handle the complexity of these schemes. The limitations of a femtocell should be studied and the schemes should be able to overcome these limitations. For example, the femtocell may have a limited bandwidth on the backhaul connection and may not be able to handle too much signalling through the backhaul. In case of cooperation among neighbouring femtocells, the overall process should be evaluated and studied.

Interference management schemes for femtocells can be mainly centralised or distributed. In the centralised schemes, there is a need of a central entity which can provide information to a particular femtocell about the global scenario. There is also a need of communication link between femtocells and the central entity, which can create extra burden and delay. On the other hand, this can also save the femtocell a lot of processing overhead required for sensing the environment and using this information. On the other hand, distributed techniques provide much flexibility to the femtocells. The femtocells can take their own decisions based on their local environment and also exchange information with its neighbouring femtocells. As compared to the centralised schemes, the distributed schemes are more complex and require self organisation and self optimisation capabilities. It needs to have specific knowledge about the macrocell users in order to avoid causing any harmful interference to it. For example, in a fully distributed algorithm, the femtocell needs to know the location of any nearby macrocell users using the same spectrum. A lot of schemes are proposed as discussed in the previous section, but there is still a need to have an efficient and less complex technique. 
Any interference management scheme strongly depends on the radio access technology (e.g CDMA or OFDMA) and access mode (CSG, open access or hybrid access) being used. Techniques like adaptive power control, resource allocation, interference cancellation and beamforming for multiple antenna transceivers can be of help in having an efficient interference management scheme. Furthermore, hybrid schemes such as joint power control and resource allocation can be very helpful. These schemes have more flexibility and can result in good performance of femtocell and macrocell. A very good and detailed study of the open challenges in femtocell deployment is provided in [128].

\section{FEMTOCELL STANDARDISATION}

In 3GPP, femtocell is standardised since release 8 where the name of femtocell is Home Node B in WCDMA system and Home e Node B in LTE system. There are many documents for $\mathrm{H}(\mathrm{e}) \mathrm{NB}$, e.g. service requirements, architectural aspects, IMS, mobility procedures, radio frequency requirements, Operation, Administration, Maintenance and Provisioning (OAM\&P) and Self Organising Networks (SON) issues are described. In this survey paper, since the interference management of femtocells are addressed, the summary of the radio frequency requirements for Home Node B [129] and radio frequency requirement for Home e Node B [130] will be described in this section.

In particular four points are analysed in [129] and [130]. 1) Guidance on how to control H(e)NB power, 2) Measurements of surrounding environment such as macro and other $\mathrm{H}(\mathrm{e}) \mathrm{NB}$ signal strength, 3) Mechanism to set maximum power and 4) Mechanism to adjust H(e)NB uplink. The objectives of these technical reports is to find out the new RF requirement for $\mathrm{H}(\mathrm{e}) \mathrm{NB}$ specific properties and to investigate the effective interference control schemes to ensure good performance of both macrocell networks and H(e)NB networks. Please note however that these analysis descriptions never have the intention to be mandatory for any proposed function in the network. These investigated area are addressed to ensure that operators have necessary information to fully understand corresponding issues on the deployment of H(e)NB. i.e. deployment scenarios potential bottlenecks, Guidance on how to control the interference between macro and $\mathrm{H}(\mathrm{e}) \mathrm{NB}$.

There are several deployment configurations consisted of the access modes mentioned before, frequency and power allocation. In the point of frequency, there are three aspects: dedicated deployment, co-channel deployment and partial cochannel deployment with the frequency used by macrocells. For the power allocation, fixed or dynamic power allocation for uplink and downlink are analysed. For LTE system, fixed and adaptive resource partitioning is also one of the factors for the deployment scenarios. In this factor, intercell interference coordination is applied by frequency, time and/or spatial partitioning. In addition to these deployment configurations, interference scenarios are investigated as table II.

For the schema of control of HNB downlink interference in [129], for example, it is observed that HNB downlink power has to depend on its location in the macrocell to adjust the acceptable performance for both HNB and Macro NB. I.e.
TABLE II

INTERFERENCE SCENARIOS IN H(E)NB

\begin{tabular}{|c|c|c|c|}
\hline S.No & Aggressor & Victim & Priority \\
\hline 1 & $\begin{array}{l}\text { UE attached to } \\
\mathrm{H}(\mathrm{e}) \mathrm{NB}\end{array}$ & $\begin{array}{l}\text { Macro (e)Node B Up- } \\
\text { link }\end{array}$ & yes \\
\hline 2 & $\mathrm{H}(\mathrm{e}) \mathrm{NB}$ & $\begin{array}{l}\text { Macro (e)Node B Up- } \\
\text { link }\end{array}$ & yes \\
\hline 3 & $\begin{array}{l}\text { UE attached to Macro } \\
\text { (e)Node B }\end{array}$ & H(e)NB Uplink & yes \\
\hline 4 & Macro (e)Node B & H(e)NB Downlink & - \\
\hline 5 & $\begin{array}{l}\text { UE attached } \\
\mathrm{H}(\mathrm{e}) \mathrm{NB}\end{array}$ & H(e)NB Uplink & yes \\
\hline 6 & $\mathrm{H}(\mathrm{e}) \mathrm{NB}$ & H(e)NB Downlink & yes \\
\hline 7 & $\begin{array}{l}\text { UE attached to } \\
\mathrm{H}(\mathrm{e}) \mathrm{NB} \text { and/or } \\
\mathrm{H}(\mathrm{e}) \mathrm{NB}\end{array}$ & Other system & - \\
\hline 8 & Other system & $\begin{array}{l}\text { UE attached to } \\
\mathrm{H}(\mathrm{e}) \mathrm{NB} \text { and/or } \\
\mathrm{H}(\mathrm{e}) \mathrm{NB}\end{array}$ & - \\
\hline
\end{tabular}

HNB allocated in the edge of macrocell needs to transmit at low power to maintain the required coverage for the UE attached to Macro NB. On the other hand, HNB allocated in the centre of macrocell has to increase its power to maintain good coverage for the UE attached in HNB while not creating much interference for the UE attached in Macro NB.

For the schema of control of HeNB downlink interference in [130], for example, there are many investigations. Time shifting at symbol level for control channel protection, frequency partition for data channel protection, and HeNB power control based on HUE measurement and/or GPS detection and so on. Some interference management specific functionalities are standardized in LTE in 3GPP Release 8 [131] and LTEAdvanced in 3GPP Release 10 [132], [133]. They are called as ICIC (Inter-cell Interference Coordination) in LTE system and eICIC (Enhanced ICIC) in LTE-Advanced system.

ICIC eNB signals to neighbour eNBs UL Interference Overload Indication (OI), UL High Interference Indication (HII) and Relative Narrowband Tx Power (RNTP) for downlink by X2 C-plane procedure (Load Information message) [134]. All of them are interference information per Physical Resource Block (PRB) to minimize interference between eNBs which cells are closed each other. The interaction between OI and HII is implementation specific, e.g. when one UE allocated in cell edge needs large power and affects high interference to the neighbour cell, the eNB informs HII in the Load Information message to the neighbour eNB to assign the PRB corresponding to HII to the user in the cell centre. When the eNB suffers from high interference from the UE in neighbour cells, the eNB inform OI in the Load Information message to request lower Tx power of the victim UE. The RNTP information is used for DL power Restriction per PRB in the cell. If eNB receives this information from neighbour eNB, it can be used for interference aware scheduling of the radio resource in the cell.

eICIC also called as time domain ICIC, the eNB signals its almost blank subframe (ABS) patterns to neighbour eNBs, so that the receiving eNB can utilize the ABS of the sending eNB with less interference. The use case of eICIC is Macro-Pico heterogeneous deployment scenarios. 
Both of functions are for eNBs and macrocell/picocell systems which need X2 interface between eNBs (means not for $\mathrm{H}(\mathrm{e}) \mathrm{NBs}$ ). In 3GPP Release 10, X2 interface between HeNBs are defined in [135], so that ICIC and eICIC are available for HeNB systems.

Each function is investigated and analysed to provide the operators to ensure the sufficient information for the deployment of $\mathrm{H}(\mathrm{e}) \mathrm{NB}$. In the future release, more and more proposals and investigations will be discussed and described for the convenience to the new categories of $\mathrm{H}(\mathrm{e}) \mathrm{NB}$ deployments.

\section{CONCLUSION \& FUTURE OF FEMTOCELlS}

Femtocells are considered to be the solution to meet the future needs for high data rates and capacity in the wireless cellular networks. However, for femtocells to become widely acceptable there are a number of challenges. Currently femtocells are being provided by operators, but due to the still low deployment numbers, the challenges are not yet apparent in practice. Femtocells would face many problems when the deployment is on a large scale and their density increases. These challenges are discussed and summarised in this article with the emphasis on interference management. This survey paper provides a basic overview of femtocells starting from their background and history. It provides an insight into the potential research areas of femtocells that can be explored. Interference management plays a vital role in the successful deployment of a wireless system, and thus it has been explained in detail with its types and perception from the point of view of different air interface technologies. The paper makes a case for the use of cognitive radio technologies to facilitate self management of FAPs. It discusses the need, requirements and research efforts till date in this area.

Although femtocells and cognitive femtocells have been a hot topic since last couple of years, they are still struggling for the large scale market acceptance. Future networks require higher capacity and data rates, better coverage, improved connectivity and QoS guarantee and soon it will not be possible for the macrocell based network to provide the required QoS to all users. In the future LTE networks, femtocells will play a vital role and with the help of opportunistic spectrum access in cognitive femtocells, it can provide the user with extra resource blocks when needed. The future cognitive femtocell would have the capability to operate as normal femtocells as well but can also use opportunistic spectrum access when a user requires higher QoS for a certain service. The femtocells would also face tough competition from the already established Wi-Fi technology and the operators need to provide cheap services in order to capture the future indoor wireless access market. Given the capabilities of femtocells, it is able to become an important part of the future wireless data and voice networks.

\section{ACKNOWLEDGMENT}

The research leading to article was dervied from the European Community's Seventh Framework Programme (FP7) under grant agreement number 248454 (QoSMOS). The authors are also thankful to the sponsoring organistion, University of Engineering \& Technology Peshawar, Pakistan.

\section{REFERENCES}

[1] V. C. M. Leung, "Internetworking wireless terminals to local area networks via radio bridges," IEEE International Conference on Selected Topics in Wireless Communications, pp. 126-129, 25-26 Jun. 1992.

[2] D. L. Perez, G. D. la Roche, A. Valcarce, A. Juttner, and J. Zhang, "Interference avoidance and dynamic frequency palnning for WiMAX femtocells networks," 11th IEEE Singapore International Conference on Communication Systems, pp. 1579-1584, 19-21 Nov. 2008.

[3] M. Reardon, "Cisco predicts wireless data explosion," Press release, 9th Feb 2010, online available.

[4] V. Chandrasekhar and J. Andrews, "Femtocell networks: A survey," IEEE Commun. Mag. , vol. 46, no. 9, pp. 59-67, Sep. 2008.

[5] M. Ismail, T. L. Doumi, and J. G. Gardiner, "Teletraffic performance of dynamic cell sectoring for mobile radio system," ICCS Conference Proceedings, vol. 3, pp. 1090-1094, 14-18 Nov. 1994.

[6] K. Hamidian and J. Payne, "Performance analysis of a CDMA/FDMA cellular communication system with cell splitting," in Proc Second IEEE Symposium on Computers and Communications, pp. 545-550, 1-3 Jul. 1997.

[7] G. L. Schrenk, "Interference management in cellular system design," 34th IEEE Vehicular Technology Conference, vol. 34, pp. 148-155, 21-23 May. 1984.

[8] M. Almgren, L. Bergstrom, M. Frodigh, and K. Wallstedt, "Channel allocation and power settings in a cellular system with macro and micro cells using the same frequency spectrum," 46th IEEE Vehicular Technology Conference, vol. 2, pp. 1150-1154, 28 Apr-1 May. 1996.

[9] Presentations by ABI Research, Picochip, Airvana, IP access, Gartner, Telefonica Espana, 2nd Intl. Conf. Home Access Points and Femtocells; available online at: http://www.avrenevents.com/dallasfemto2007/purchase presentations.htm.

[10] J. Cullen, "Radioframe presentation," in Femtocell Europe , London, UK, June. 2008.

[11] M. Yavuz, F. Meshkati, S. Nanda, A. Pokhariyal, N. Johnson, B. Roghothaman, and A. Richardson, "Interference management and performance analysis of umts/hspa+ femtocells," IEEE Commun. Mag. , vol. 47, no. 9, pp. 102-109, Sep. 2009.

[12] H. Daehyoung, C. Seungwoong, and C. Jaeweon, "Coverage and capacity analysis for the multi layer cdma macro/indoor picocells," IEEE International Conference on Communications, vol. 1, pp. 354358, 1999.

[13] H. Yankikomeroglu and E. S. Sousa, "Power control and number of antenna elements in cdma distributed antenna systems," IEEE International Conference on Communications, vol. 2, pp. 1040-1045, 7-11 Jun 1998.

[14] H. Yanikomeroglu and E. S. Sousa, "CDMA distributed antenna system for indoor wireless communications," IEEE Int. Conf. on Universal Personal Communications, pp. 990-994, Oct. 1993.

[15] J. Zhang and J. G. Andrews, "Distributed antenna system with randomness," IEEE Trans. Wireless Commun., vol. 7, no. 9, pp. 3636-3646, Sept 2008.

[16] T. Wirth, L. Thiele, T. Haustein, O. Braz, and J. Stefanik, "LTE amplify and forward relaying for indoor coverage extension," IEEE 72nd Vehicular Technology Conference Fall, vol. 147, pp. 1-5, Oct. 2010.

[17] V. Venkatkumar, T. Wirth, T. Haustein, and E. Schulz, "Relaying in long term evolution: Indoor full frequency reuse," European Wireless (EW), vol. 149, pp. 298-302, May 2009.

[18] T. Wirth, V. Venkatkumar, T. Haustein, E. Schulz, and R. Halfmann, "LTE-advanced relaying for outdoor range extension," in VTC2009. Fall, Anchorage, USA, pp. 1-4, Sep. 2009.

[19] H. Claussen, "Performance of macro and co channel femtocells in a hierarchical cell structure," IEEE 18th International Symposium on Personal, Indoor and Mobile Radio Communications, pp. 1-5, 3-7 Sep. 2007.

[20] L. T. W. Ho and H. Claussen, "Effects of user-deployed, co-channel femtocells on the call drop probability in a residential scenario," IEEE 18th International Symposium on Personal, Indoor and Mobile Radio Communications, pp. 1-5, 3-7 Sept. 2007.

[21] R. Baines, "The need for WiMAX picocell and femtocells," WiMax London, pp. 1-36, 25-26 April 2007.

[22] J. Xiang, Y. Zhang, T. Skeie, and L. Xie, "Downlink spectrum sharing for cognitive radio femtocell networks," IEEE Systems Journal, vol. 4, no. 4, pp. 524-534, Dec. 2010.

[23] S. M. Cheng, W. C. Ao, and K. C. Chen, "Downlink capacity of twotier cognitive femto networks," IEEE 21st International Symposium on 
Personal Indoor and Mobile Radio Communications, pp. 1303-1308, 26-30 Sept. 2010.

[24] J. P. M. Torregoza, R. Enkhbat, and W.-J. Hwang, "Joint power control, base station assignment and channel assignment in cognitive femtocell networks," EURASIP Journal on wireless communications and networking, 2010.

[25] J. Xiang, Y. Zhang, and T. Skeie, "Dynamic spectrum sharing in cognitive radio femtocell networks," 4th International conference of access networks (ACCESSNET), vol. 37, pp. 164-178, 2009.

[26] M. E. Sahin, I. Guvenc, and H. Arslan, "Uplink user signal separation for ofdma based cognitive radios," EURASIP Journal on advances in signal processing, 2010.

[27] D. Chambers, "Femtocell history," online available at: http://www.thinkfemtocell.com/FAQs/femtocell-history.html.

[28] Femto Forum, http://www.femtoforum.org/femto/.

[29] 3GPP release 8, Online available at: http://www.3gpp.org/Release-8.

[30] R. Tang, "Indoor propagation in cellular/PCS system design," Emerging Technologies Symposium Wireless Communications and Systems, pp. 81-84, 1999

[31] M. Fan, M. Yavuz, S. Nanda, Y. Tokgoz, and F. Meshkati, "Interference management in femto cell deployment," in 3GPP2 Femto Workshop, Oct. 2007.

[32] S. F. Hasan, N. H. Siddique, and S. Chakraborty, "Femtocell versus Wi Fi- A survey and comparison of architecture and performance," 1st International Conference on Wireless Communication, Vehicular Technology, Information Theory and Aerospace and Electronic Systems Technology, pp. 916-920, 17-20 May 2009.

[33] http://www.samsung.com.

[34] http://www.ipaccess.com/femtocells.

[35] http://www.ubiquisys.com

[36] http://www.huawei.com.

[37] S. S. Prasad and R. Baruah, "Femtocell mass deployment: Indian perspective," 3rd International Conference on Anti-counterfeiting, Security, and Identification in Communication, pp. 34-37, 20-22 Aug. 2009.

[38] J. O. Carroll, H. Claussen, and L. Doyle, "Partial GSM spectrum reuse for femtocells," IEEE 20th International Symposium on Personal, Indoor and Mobile Radio Communications, pp. 2111-2116, 13-16 Sept. 2009.

[39] Ericsson. (2008, Sep) Press release. Available online at: http://www.ericsson.com/ericsson/press/releases/200809111250616.shtml.

[40] M. Neruda, J. Vrana, and R. Bestak, "Femtocells in 3G mobile networks," 16th International Conference on Systems, Signals and Image Processing, pp. 1-4, 18-20 June. 2009.

[41] D. Knisely, T. Yoshizawa, and F. Favichia, "Standardization of femtocells in 3GPP," IEEE Commun. Mag. , vol. 47, no. 9, pp. 68-75, Sept. 2009.

[42] Y. Tokgoz, F. Meshkati, Y. Zhou, M. Yavuz, and S. Nanda, "Uplink interference management for hspa+ and 1xevdo femtocells," IEEE Global Telecommunications Conference, pp. 1-7, Nov. 30 2009-Dec. 42009.

[43] M. Z. Chowdhury, R. Won, R. Eunjun, and M. J. Yeong, "Handover between macrocell and femtocell for umts based networks," 11th International Conference on Advanced Communication Technology, vol. 1, pp. 237-241, 15-18 Feb. 2009.

[44] A. Golaup, M. Mustapha, and L. B. Patanapongipibul, "Femtocell access control strategy in umts and lte," IEEE Commun. Mag. , vol. 47, no. 9, pp. 117-123, Sep. 2009.

[45] L. Wang, Z. Yongsheng, and W. Zhenrong, "Mobility management schemes at radio network layer for lte femtocells," IEEE 69th Vehicular Technology Conference, pp. 1-5, 26-29 April. 2009.

[46] R. Y. Kim, S. K. Jin, and K. Etemad, "WiMAX femtocell: requirements, challenges, and solutions," IEEE Commun. Mag. , vol. 47, no. 9, pp. 84-91, Sept. 2009.

[47] D. Williams, "WiMAX femtocells a technology on demand for cable MSOs," in Femtocells Europe, Jun. 2008.

[48] D. Lopez-Perez, A. Juttner, and J. Zhang, "Optimisation methods for dynamic frequency planning in ofdma networks," Networks , Budapest, Hungary, Sept. 2008.

[49] H. Su, L. Kuang, and J. Lu, "Interference avoidance in OFDMA based femtocell network," IEEE Youth Conference on Information, Computing and Telecommunication, pp. 126-129, 20-21 Sept. 2009.

[50] B. Yong, Z. Juejia, and C. Lan, "Hybrid spectrum usage for overlaying LTE macrocell and femtocell," IEEE Global Telecommunications Conference, pp. 1-6, Nov. 30-Dec. 42009.
[51] D. Lopez-Perez, A. Valcarce, G. de la Roche, and Z. Jie, "OFDMA femtocells: A roadmap on interference avoidance," IEEE Commun. Mag. , vol. 47, no. 9, pp. 41-48, Sep. 2009.

[52] D. Lopez-Perez, A. Ladanyi, A. Juttner, and Z. Jie, "OFDMA femtocells: A self-organizing approach for frequency assignment," IEEE 20th International Symposium on Personal, Indoor and Mobile Radio Communications, pp. 2202-2207, 13-16 Sept. 2009.

[53] N. Shetty, S. Parekh, and J. Walrand, "Economics of femtocells," IEEE Global Telecommunications Conference, pp. 1-6, Nov. 30-Dec. 42009.

[54] H. Wallop, "Vodafone: guarantees home coverage with 50 femtocell," Telegraph, 18 January, 2010. Available online at: http://www.telegraph.co.uk/technology/mobilephones/7019873/Vodafone-guarantees-home-coverage-with-50femtocell.html.

[55] http://www.motorola.com.

[56] http://www.node-h.com/MWC2010.html.

[57] M. Latham, "Consumer attitudes to femtocell enabled in-home services-insights from a european survey," in Femtocells Europe, London, Jun. 2008.

[58] D. Choi, P. Monajemi, S. Kang, and J. Villasenor, "Dealing with loud neighbours: The benefits and tradeoffs of adaptive femtocell access," IEEE Global Telecommunications Conference, pp. 1-5, Nov. 30-Dec. 42008.

[59] D. Lopez-Perez, A. Valcarce, G. Roche, E. Liu, and J. Zhang, "Access methods to wimax femtocells: A downlink system-level case study," 11th IEEE Singapore International Conference on Communication Systems, pp. 1657-1662, 19-21 Nov. 2008.

[60] D. Das and V. Ramaswamy, "Co-channel femtocell-macrocell deployments-access control," IEEE 70th Vehicular Technology Conference Fall, pp. 1-6, 20-23 Sept. 2009.

[61] A. Valcarce, D. Lopez-Perez, G. D. L. Roche, and Z. Jie, "Limited access to ofdma femtocells," IEEE 20th International Symposium on Personal, Indoor and Mobile Radio Communications, pp. 1-5, 13-16 Sept. 2009.

[62] G. de la Roche, A. Valcarce, D. Lopez-Perez, and Z. Jie, "Access control mechanisms for femtocells," IEEE Commun. Mag. , vol. 48, no. 1, pp. 33-39, Jan. 2010.

[63] Z. Haijun, W. Xiangming, W. Bo, Z. Wei, and S. Yong, "A novel handover mechanism between femtocell and macrocell for lte based networks," Second International Conference on Communication Software and Networks, pp. 228-231, 26-28 Feb. 2010.

[64] S. Wu, X. Zhang, R. Zheng, Z. Yin, Y. Fang, and D. Yang, "Handover study concerning mobility in the two-hierarchy network," IEEE 69th Vehicular Technology Conference, 2009. VTC Spring 2009, pp. 1-5, 26-29 April 2009.

[65] K. Jin-Seok and L. Tae-Jin, "Handover in umts networks with hybrid access femtocells," The 12th International Conference on Advanced Communication Technology, vol. 22, pp. 904-908, 7-10 Feb. 2010.

[66] M. Z. Chowdhury, R. Won, R. Eunjun, and J. M. Yeong, "Handover between macrocell and femtocell for umts based networks," 11th International Conference on Advanced Communication Technology, vol. 1, pp. 237-241, 15-18 Feb. 2009.

[67] A. A. Habeeb and M. A. Qadeer, "Interference evaluation and ms controlled handoff technique for femtocell," First Asian Himalayas International Conference on Internet, pp. 1-5, 3-5 Nov. 2009.

[68] J. S. Young, G. H. Hae, and K. S. Kwang, "A self organised femtocell for ieee 802.16e system," IEEE Global Telecommunications Conference, pp. 1-5, Nov. 30-Dec. 42009.

[69] J. L. V. D. Berg, R. Litjens, A. Eisenbltter, M. Amirijoo, O. Linnell, C. Blondia, T. Krner, N. Scully, J. Oszmianski, and L. C. Schmelz, "Self-organisation in future mobile communication networks," ICT Mobile Summit, Sweden, vol. 2, pp. 915-920, June, 2008.

[70] K. Zetterberg, N. S. ans J Turk, L. Jorgueski, and A. Pais, "Controllability for self-optimisation of home enodebs," COST 2100, Joint Workshop COST 2100 SWG 3.1 and FP7-ICT-SOCRATES, Greece, February, 2010.

[71] I. Balan, "Self-optimisation in 3gpp lte networks," December, 2009.

[72] N. Jin-Kyu, S. Won-Kyeong, K. Dong-Won, C. Jae-In, and C. You-Ze, "A network-assisted femto base station management scheme in ieee 802.16e system," 7th IEEE Consumer Communications and Networking Conference, pp. 1-2, 9-12 Jan. 2010.

[73] H. S. Jo, C. Mun, J. Moon, and J. G. Yook, "Self-optimized coverage coordination in femtocell networks," IEEE Trans. Wireless Commun., vol. 9, no. 10, pp. 2977-2982, Oct 2010.

[74] A. Saatsakis, P. Demestichas, V. Merat, C. L. Page, T. Loewel, and K. Nolte, "Femtocell and flexible base station cognitive management," IEEE 20th International Symposium on Personal, Indoor and Mobile Radio Communications, pp. 1-5, 13-16 Sept. 2009. 
[75] H. Chan, C. Hyoung-Kee, and K. In-Hwan, "Building femtocell more secure with improved proxy signature," IEEE Global Telecommunications Conference, pp. 1-6, Nov. 30-Dec. 42009.

[76] T. Chiba and H. Yokota, "Efficient route optimization methods for femtocell-based all ip networks," IEEE International Conference on Wireless and Mobile Computing, Networking and Communications, pp. 221-226, 12-14 Oct. 2009.

[77] N. I. of Standards and Technology, Ieee1588 website, http://ieee1588.nist.gov/, 2008.

[78] I. Hwang, Y. Kang, H. Kim, and S. Kim, "Synchronization issue for mobile wimax femtocell," International Conference on Information and Communication Technology Convergence, vol. 65, pp. 563-564, 17-19 Nov. 2010.

[79] S. Lee, "An enhanced ieee 1588 time synchronization algorithm for asymmetric communication link using block burst transmission," IEEE Commun. Lett., vol. 12, no. 9, pp. 687-689, Sep. 2008.

[80] "Femtocell synchornisation," by Adrio Communications Ltd. Available online at: www.radio-electronics.com.

[81] T. Wada, N. Saitou, T. Hara, and M. Okada, "Frame synchronization among base stations for tdd systems," 4th International Symposium on Communications, Control and Signal Processing, pp. 1-4, 3-5 Mar. 2010.

[82] J. Yoon, J. Lee, and H. S. Lee, "Multi-hop based network synchronization scheme for femtocell systems," IEEE 20th International Symposium on Personal, Indoor and Mobile Radio Communications, pp. 1-5, Sept. 2009.

[83] V. Chandrasekhar and J. G. Andrews, "Spectrum allocation in tiered cellular networks," IEEE Trans. Commun., vol. 57, no. 10, pp. 30593068, Oct. 2009.

[84] J. Han-Shin, M. Cheol, M. June, and Y. Jong-Gwan, "Interference mitigation using uplink power control for two tier femtocell networks," IEEE Trans. Wireless Commun., vol. 8, no. 10, pp. 4906-4910, October 2009.

[85] J. G. Andrews, "Interference cancellation for cellular systems: A contemporary overview," IEEE Wireless Commun., vol. 2, no. 3, pp. 19-29, April. 2005.

[86] M. F. Madkour, S. C. Gupta, and Y. P. E. Wang, "Successive interference cancellation algorithms for downlink w-cdma communications," IEEE Trans. Wireless Commun., vol. 1, no. 1, pp. 169-177, Jan 2002.

[87] F. Berggren and S. B. Slimane, "Successive interference cancellation in multi-rate ds-cdma systems," 14th IEEE Proc. Personal, Indoor and Mobile Radio Communications, vol. 2, pp. 1752- 1756, 7-10 Sept. 2003.

[88] S. P. Weber, J. Andrews, X. Yang, and G. de Veciana, "Transmission capacity of wireless ad hoc networks with successive interference cancellation," IEEE Trans. Inf. Theory, vol. 53, no. 8, pp. 2799-2814, Aug. 2007

[89] D. Divsalar and M. K. Simon, "Improved cdma performance using parallel interference cancellation," IEEE Military Communications Conference, vol. 3, pp. 911-917, 2-5 Oct. 1994.

[90] L. G. F. Trichard, J. S. Evans, and I. B. Collings, "Large system analysis of linear parallel interference cancellation," IEEE International Conference on Communications, vol. 1, pp. 26-30, 11-14 Jun. 2001.

[91] P. Frenger, P. Orten, and T. Ottosson, "Code spread cdma with interference cancellation,” IEEE J. Sel. Areas Commun., vol. 17, no. 12, pp. 2090-2095, 1999.

[92] P. Patel and J. Holtzman, "Analysis of a simple successive interference cancellation scheme in a ds/cdma system," IEEE J. Sel. Areas Commun., vol. 12, no. 5, pp. 796-807, Jun. 1994.

[93] F. Wijk, G. Janssen, and R. Prasad, "Groupwise successive interference cancellation in a ds/cdma system," Sixth IEEE International Symposium on Personal, Indoor and Mobile Radio Communications, Wireless: Merging onto the Information Superhighway, pp. 742-746, 27-29 Sep 1995.

[94] M. Ghosh, "Co-channel interference cancellation for hdtv receivers," IEEE International Conference on Acoustics, Speech, and Signal Processing, vol. 5, pp. 2675-2678, 1999.

[95] D. Hallen, J. Holtzman, and Z. Zvonar, "Multiuser detection for cdma systems," IEEE Personal Commun., pp. 46-58, April 1995.

[96] M. Honig, U. Madhow, and S. Verdu, "Blind adaptive multiuser detection," IEEE Trans. Inf. Theory, vol. 41, no. 4, pp. 944-960, July 1995.

[97] R. S. Karlsson, "Radio resource sharing and capacity of some multiple access methods in hierarchical cell structures," in Vehicular Technology Conference, vol. 5, pp. 2825-2829, Sep. 1999.

[98] K. Han, Y. Choi, D. Kim, M. Na, S. Choi, and K. Han, "Optimization of femtocell network configuration under interference constraints," 7 th
International Symposium on Modeling and Optimization in Mobile, Ad Hoc, and Wireless Networks, pp. 1-7, 23-27 Jun. 2009.

[99] T. Zahir, K. Arshad, Y. Ko, and K. Moessner, "A downlink power control scheme for interference avoidance in femtocells," 7th International Wireless Communications and Mobile Computing Conference (IWCMC), 2011, pp. 1222-1226, 4-8 July 2011.

[100] A. K. Elhakeem, R. D. Girolamo, I. B. Bdira, and M. Talla, "Delay and throughput characteristics of th, cdma, tdma, and hybrid networks for multipath faded data transmission channels," IEEE J. Se. Areas Commun., vol. 12, no. 4, pp. 622-637, May 1994.

[101] V. Chandrasekhar and J. G. Andrews, "Uplink capacity and interference avoidance for two-tier femtocell networks," IEEE Trans. Wireless Commun., vol. 8, no. 7, pp. 3498-3509, Jul. 2009.

[102] J. Espino and J. Markendahl, "Analysis of macro femtocell interference and implications for spectrum allocation," IEEE 20th International symposium on personal, indoor and mobile radio communicaionts, pp. 2208-2212, 13-16 Sep. 2009.

[103] H. Claussen and F. Pivit, "Femtocell coverage optimization using switched multi-element antennas," IEEE ICC, Germany, June 2009.

[104] X. Li, L. Qian, and D. Kataria, "Downlink power control in co-channel macrocell femtocell overlay," 43rd Annual Conference on Information Sciences and Systems, pp. 383-388, 18-20 Mar. 2009.

[105] G. T. 25.820, "3g home nodeb study item technical report (release 8)," Sept. 2008.

[106] W. Yi, Z. Dongmei, J. Hai, and W. Ye, "A novel spectrum arrangement scheme for femtocell deployment in lte macrocells," IEEE 20th Symposium on personal, indoor and mobile radio communications, $\mathrm{pp}$. 6-11, 13-16 Sep. 2009.

[107] L. Poongup, L. Taeyoung, J. Jangkeun, and S. Jitae, "Interference management in lte femtocell systems using fractional frequency reuse," The 12th International Conference on Advanced Communication Technology, vol. 2, pp. 1047-1051, 7-10 Feb. 2010.

[108] L. Yang-Yang, M. Macuha, E. S. Sousa, T. Sato, and M. Nanri, "Cognitive interference management in 3g femtocells," IEEE 20th International symposium on personal, indoor and mobile radio communications, pp. 1118-1122, 13-16 Sep. 2009.

[109] M. E. Sahin, I. Guvenc, M.-R. Jeong, and H. Arslan, "Handling cci and ici in ofdma femtocell networks through frequency scheduling," IEEE Trans. Consum. Electron., vol. 55, no. 4, pp. 1936-1944, Nov. 2009.

[110] S. Qinliang, H. Aiping, W. Zhouyun, Y. Guanding, Z. Zhaoyang, $\mathrm{X}$. Kai, and Y. Jin, "A distributed dynamic spectrum access and power allocation algorithm for femtocell networks," International Conference on Wireless Communications and Signal Processing, pp. 1-5, 13-15 Nov. 2009

[111] M. Rahman and H. Yanikomeroglu, "Enhancing cell-edge performance: a downlink dynamic interference avoidance scheme with inter-cell coordination," IEEE Trans. Wireless Commun., pp. 1414-1425, April 2010.

[112] V. Chandrasekhar, J. G. Andrews, T. Muharemovic, Z. Shen, and A. Gatherer, "Power control in two-tier femtocell networks," IEEE Trans. Wireless Commun., vol. 8, no. 8, pp. 4316-4328, Aug. 2009.

[113] V. Chandrasekhar, J. G. Andrews, S. Zukang, T. Muharemovic, and A. Gatherer, "Distributed power control in femtocell-underlay cellular networks," IEEE Global Telecommunications Conference, pp. 1-6, Nov. 30-Dec. 42009.

[114] P. Sangkyu and B. Saewoong, "Dynamic inter-cell interference avoidance in self-organizing femtocell networks," IEEE International Conference on Communications (ICC) 2011, pp. 1-5, 5-9 June 2011.

[115] A. Adhikary, V. Ntranos, and G. Caire, "Cognitive femtocells: Breaking the spatial reuse barrier of cellular systems," Information Theory and Applications Workshop (ITA), 2011, pp. 1-10, 6-11 Feb. 2011.

[116] N. Arulselvan, V. Ramachandran, S. Kalyanasundaram, and H. Guang, "Distributed power control mechanisms for hsdpa femtocells," IEEE 69th Vehicular Technology Conference, pp. 1-5, 26-29 Apr. 2009.

[117] T. Akbudak and A. Czylwik, "Distributed power control and scheduling for decentralized ofdma networks," International ITG Workshop on Smart Antennas, pp. 59-65, 23-24 Feb. 2010.

[118] H. Zhenglei, Z. Zhimin, X. Hailun, and S. Junfeng, "Power control in two-tier ofdma femtocell networks with particle swarm optimization," IEEE 73rd Vehicular Technology Conference (VTC Spring), 2011, pp. 1-5, 15-18 May 2011.

[119] I. Ashraf, H. Claussen, and L. T. W. Ho, "Distributed radio coverage optimization in enterprise femtocell networks," IEEE International Conference on Communications (ICC), pp. 1-6, May 2010.

[120] Z. Yalin, Y. Yang, E. S. Sousa, and Z. Qinyu, "Pilot power minimization in hsdpa femtocells," IEEE Global Telecommunications Conference GLOBECOM, 2010, pp. 1-5, 6-10 Dec 2010. 
[121] H. Claussen, L. T. W. Ho, and L. G. Samuel, "Self-optimization of coverage for femtocell deployments," Wireless Telecommunications Symposium. WTS 2008, pp. 278-285, 24-26 April 2008.

[122] S. Al-Rubaye, A. Al-Dulaimi, and J. Cosmas, "Pilot power optimization for autonomous femtocell networks," Wireless Advanced (WiAd), 2011, pp. 170-175, 20-22 June 2011.

[123] L. Yizhe, F. Zhiyong, Z. Qixun, T. Li, and T. Fang, "Cognitive optimization scheme of coverage for femtocell using multi-element antenna," IEEE 72nd VTC, pp. 1-5, Sept 2010 .

[124] E. J. Hong, S. Y. Yun, and D.-H. Cho, "Decentralized power control scheme in femtocell networks: A game theoretic approach," IEEE 20th International Symposium on Personal, Indoor and Mobile Radio Communications, pp. 415-419, 13-16 Sept. 2009.

[125] S. Barbarossa, S. Sardellitti, A. Carfagna, and P. Vecchiarelli, "Decentralized interference management in femtocells: A game-theoretic approach," Proceedings of the Fifth International Conference on Cognitive Radio Oriented Wireless Networks and Communications (CROWNCOM), pp. 1-5, June 2010.

[126] W. chih Hong and Z. Tsai, "On the femtocell-based mvno model: A game theoretic approach for optimal power setting," IEEE 71st Vehicular Technology Conference (VTC 2010-Spring), pp. 1-5, May 2010.

[127] H.-C. Lee, D.-C. Oh, and Y.-H. Lee, "Mitigation of inter-femtocell interference with adaptive fractional frequency reuse," IEEE International Conference on Communications (ICC), pp. 1-5, May 2010.

[128] N. Saquib, E. Hossain, L. B. Le, and D. I. Kim, "Interference management in ofdma femtocell networks: Issues and approaches," IEEE Wireless Commun., to appear. [Online]. Available: http://www.ee.umanitoba.cal ekram/wcm-femto.pdf.

[129] 3GPP TR25.967 : FDD Home Node B (HNB) RF Requirements, available online at http://www.3gpp.org/ftp/Specs/html-info/25967.htm.

[130] 3GPP TR36.921: FDD Home eNode B(HeNB) RF Requirement analysis, available online at http://www.3gpp.org/ftp/Specs/htmlinfo/36921.htm.

[131] 3GPP TS36.300 E-UTRA and E-UTRAN overview description stage 2 (Release 8), available online at http://3gpp.org/ftp/Specs/2010-12/Rel8/36series/36300-8c0.zip.

[132] 3GPP TS36.300 E-UTRA and E-UTRAN overview description stage 2 (Release 10), available online at http://3gpp.org/ftp/Specs/2010-12/Rel10/36series/36300-a20.zip.

[133] RP-101229 RAN2 CRs on Core part: Enhanced ICIC for non-CA based deployments of heterogeneous networks for LTE, available online at http://3gpp.org/ftp/tsg-ran/TSG-RAN/TSGR-50/Docs/RP-101229.zip.

[134] 3GPP TS36.423 E-UTRAN X2 application protocol (X2AP) (Release 8), available online at http://3gpp.org/ftp/Specs/2010-12/Rel8/36series/36423-890.zip.

[135] RP-101222 RAN2 CR on Core part: HNB and HeNB Mobility Enhancements, available online at http://3gpp.org/ftp/tsg-ran/TSGRAN/TSGR-50/Docs/RP-101222.zip. 